\title{
Neoliberalismo durável: o Consenso de Washington na Onda Rosa Latino-Americana
}

\author{
Augusto Neftali Corte de Oliveira ${ }^{1}$ (D)
}

\begin{abstract}
Este artigo investiga a permanência do neoliberalismo na política eleitoral latinoamericana durante a Onda Rosa, mostrando sua presença nas plataformas presidenciais lançadas entre 1999 e 2015 . Com esse objetivo, desenvolve uma estratégia de análise de conteúdo baseada nas regras do Consenso de Washington, espécie de manifesto programático do neoliberalismo. Foram analisados 94 programas de governo, de 47 eleições presidenciais ocorridas em 13 países da América Latina. A pesquisa revela que o neoliberalismo realmente perdeu espaço e que algumas regras do Consenso de Washington, como a privatização e a redução do gasto público, foram enfaticamente rejeitadas. Já o espaço ocupado por regras como o controle da inflação e a redução do déficit público mostra a resiliência neoliberal durante a Onda Rosa, mesmo em parte dos programas de governo dos presidentes não neoliberais. Na medida em que dimensiona a presença do Consenso de Washington na cena política da América Latina dos anos 2000, esta investigação ajuda a refletir sobre os limites da agenda contrária ao neoliberalismo e as bases da retomada dessa ideologia no subcontinente.
\end{abstract}

Palavras-chave: ideologia; eleições presidenciais; programas de governo; partidos políticos

\section{Introdução}

Enquanto movimento político, o neoliberalismo se consolidou na paisagem ideológica da América Latina a partir do final da década de 1980 e início da década de 1990, especialmente com a difusão das propostas conhecidas como Consenso de Washington (CW). Originalmente, o neoliberalismo aparece como resposta política - mas também técnica econômica - ao desafio da estagflação (Notermans, 2000). A percepção de que a orientação heterodoxa ou keynesiana, adotada tanto por governos socialdemocratas quanto por conservadores no pós-guerra, não oferecia respostas adequadas no final da década de 1970 favoreceu a adoção das propostas neoliberais.

$\mathrm{Na}$ América Latina, as experiências neoliberais se iniciaram em alguns países concomitantemente às dos países centrais do Ocidente. O caso do Chile é paradigmático,

\footnotetext{
${ }^{1}$ Pontifícia Universidade Católica do Rio Grande do Sul (PUCRS). Escola de Humanidades, Programa de PósGraduação em Ciências Sociais. Porto Alegre, RS, Brasil. E-mail: augusto.oliveira@pucrs.br
} 
considerando sua antecedência. As iniciativas neoliberais manejadas pelos Chicago Boys ${ }^{2}$ assumiram papel central na ditadura de Pinochet entre 1973 e 1990 . Posteriormente, o neoliberalismo foi adotado como resposta à crise da dívida externa sentida em diferentes países da América Latina no contexto da moratória mexicana de 1982 (Vanden e Prevost, 2002, p. 165).

Em países governados democraticamente, chamou a atenção o fato de que o neoliberalismo muitas vezes foi adotado de surpresa, isto é, por presidentes que, enquanto candidatos, defendiam propostas diferentes. Stokes (2001, p. 13) encontrou essa situação em oito países do subcontinente entre 1982 e 1995. O mesmo argumento aparece em Anderson (1998, p. 20). A defesa de políticas direcionadas à eficiência econômica, sob o potencial custo da segurança social (já bastante limitada) dos eleitores latino-americanos, era percebida pelos candidatos presidenciais como inviável para sustentar uma campanha eleitoral vitoriosa.

Com ou sem a aprovação inicial das urnas, a ideologia neoliberal tornou-se central na política da América Latina até ser desafiada, no início dos anos 2000, pela ascensão de candidatos críticos às presidências nacionais. A eleição de Chávez, na Venezuela em 1998, de Lula, no Brasil em 2002, de Kirchner, na Argentina em 2003, de Vázquez, no Uruguai em 2004, de Morales, na Bolívia em 2005, de Correa, no Equador em 2006, de Funes, em El Salvador em 2009, de Humala, no Peru em 2011, dentre outros, podem ser consideradas representativas de um processo político latino-americano que diverge, ou mesmo antagoniza, com a predominância neoliberal da década de 1990.

Para autores como Lora e Oliveira (2015), Coutinho (2006), Gallegos (2006), Murillo, Oliveros e Vaishanav (2010), Baker e Greene (2011), Clark e North (2018), esse movimento expressou a rejeição, por parte dos eleitores, das políticas neoliberais e de suas consequências na América Latina. A virada política na América Latina foi identificada por Marea Rosa ou Pink Tide (Lopes e Faria, 2016), uma Onda Rosa. De acordo com Gonzalez (2019, p. 7), o termo foi cunhado pelo correspondente do New York Times em Montevidéu, Frank Lehrer, e incorretamente atribuído a Hugo Chávez.

\footnotetext{
2 Chicago Boys é a designação de um grupo de economistas neoconservadores chilenos formados em um convênio entre a Universidade Católica do Chile e a Universidade de Chicago (Loveman, 2001, p. 282; Silva, 2002, p. 455; Gonzalbo, 2015, p. 107). Sua origem está em um programa de bolsas do governo dos Estados Unidos voltado para modernização dos estudos econômicos na América Latina, intermediado pela Fundação Ford a partir de 1956. Durante o governo Pinochet, especialmente após 1975, os Chicago Boys controlaram a política econômica chilena e implementaram um programa ortodoxo de estabilização econômica contra a inflação, adotando a redução do gasto público e políticas de livre mercado por meio de privatização e desregulamentação financeira. A natureza ditatorial do regime protegeu e insulou o projeto político e econômico dos Chicago Boys contra pressões dos setores assalariados e de renda média da população, bem como - o que nem sempre é reparado - dos interesses do setor empresarial tradicional do Chile, que foi profundamente transformado (Clark, 2018). Gonzalbo (2015, p. 110) considera que a experiência chilena, respaldada por Friedrich Hayek e Milton Friedman, marcou a história do neoliberalismo, pois foi sua primeira adoção enquanto regra política geral de um governo.
} 
Embora o fenômeno da Onda Rosa não possa ser resumido a uma contraposição ao neoliberalismo, sua relação com a ruptura do modelo econômico está bem documentada na literatura acadêmica, como aponta a revisão de Ruckert, MacDonald e Proulx (2017) sobre a ideia de "pós-neoliberalismo". O conceito de "pós-neoliberalismo" remeteu originalmente à rejeição - tanto intelectual quanto política - da permanência do neoliberalismo no centro da cena político-governamental (como na tese sobre o fim da história). Essa acepção do conceito ocorre nos diferentes textos de Sader e Gentili (1998). Por exemplo, nas afirmações "não sei quando, mas o pós-neoliberalismo chegará" (Therborn, 1998, p. 184) e "o pós-neoliberalismo é, ainda, uma etapa em construção" (Borón, 1998, p. 186). Posteriormente, o termo passou a designar os governos "pósneoliberais" da Onda Rosa na América Latina, não excluindo outras abordagens como a do "novo-desenvolvimentismo"3 e do "buen vivir"4.

Tanto as razões de rejeição do neoliberalismo quanto as alternativas apresentadas respondem a diferentes estratégias discursivas contextuais em torno da questão econômica, da participação popular, da inclusão social e da proteção ambiental. Como ressalta Coutinho (2006, p. 122), ao contrário da tendência homogeneizadora das reformas neoliberais inspiradas no CW durante os anos 1990, observa-se uma diversidade expressiva nas alternativas críticas ao neoliberalismo na América Latina. No mesmo sentido, Angel e López-Londoño (2019), após análise dos discursos de investidura dos presidentes da Onda Rosa na América do Sul, concluem que o traço retórico comum de rejeição ao neoliberalismo não está acompanhado de uma mesma e igual estratégia alternativa.

Apesar das divergências específicas relacionadas a casos particulares ou à amplitude do processo ${ }^{5}$, bem como à complexidade em torno das alternativas realmente apresentadas, um observador da cena latino-americana na primeira década dos anos 2000 poderia esperar que as inovações econômicas democraticamente induzidas consolidassem uma estratégia político-econômica de longa duração na região, a exemplo do consenso

\footnotetext{
3 O termo é empregado por Bresser-Pereira e Theuer (2012) para identificar estratégias desenvolvimentistas com características sociais e nacionais na América Latina recente. Por outro lado, pensando no caso brasileiro, Sallum Jr. e Goulart (2016) destacam a continuidade entre os governos e a diversidade das políticas adotadas, na síntese menos precisa de um desenvolvimentismo liberal.

${ }^{4}$ Silva e Guedes (2017) destacam que o uso de "buen vivir" no Equador e na Bolívia carrega elementos de pluralismo, reconhecimento e relacionamento com o ambiente bastante salientes quando comparados com a visão do "novo-desenvolvimentismo". Contudo, Cubillo-Guevara (2016) identifica no uso político-eleitoral do termo uma apropriação imprecisa do "Sumak Kawsay" pensado no Movimento Indígena Equatoriano, um conceito omnibus tornado análogo ao de desenvolvimento "pós-neoliberal" na região andina. A análise de Cuestas-Caza (2019) revela uma relação complexa entre "buen vivir" e "Sumak Kawsay", facetada pela lente de interpretação adotada e pelas estratégias investigativas. Ela ilustra, para o presente artigo, a especificidade e a complexidade do estudo sobre o conteúdo positivo da Onda Rosa da América Latina.

5 Existe uma ressalva bem conhecida ao argumento da superação do neoliberalismo. Diz respeito à manutenção de pressupostos neoliberais na gestão da política econômica e social, a baixa articulação das inovações manejadas em um modelo de desenvolvimento alternativo e os déficits de inclusão social e política não atacados. O argumento é articulado para a América Latina por Garretón e outros (2007); para Argentina e Chile por Undurraga (2015); para o Brasil por Boito Jr. e Berringer (2013) e Boito Jr. (2016).
} 
social-democrata durante os Trinta Gloriosos na Europa ocidental. Extrapolando a proposição de Bresser-Pereira e Theuer (2012) e Ruckert, MacDonald e Proulx (2017), que não deixam de pontuar desafios para a resiliência das experiências econômicas da Onda Rosa, poder-se-ia imaginar uma situação na qual as forças político-eleitorais antagônicas entrassem em disputassem em torno do novo modelo (ou modelos) desenvolvimentista e abandonassem decisivamente o neoliberalismo.

Contudo, seja como parte dos conteúdos discursivos antagônicos à Onda Rosa, ou mesmo incorporados nos próprios discursos de seus presidentes, os paradigmas da política neoliberal continuaram ocupando um espaço relevante na política da América Latina. Recentemente, quando inovações políticas ocorreram democraticamente (na Argentina, com a eleição de Mauricio Macri, em 2015) ou por outras vias (no Brasil, a partir do impeachment que levou à Presidência Michel Temer, em 2016), o neoliberalismo rapidamente reapareceu na disputa pela condução da política econômica. Aponta-se, assim, para o final do ciclo "progressista" na América Latina (Gaudichaud, 2016, 2019; Lopes e Faria, 2016; Silva, 2019; Gonzalez, 2019). Onde e sob qual feição o neoliberalismo resistiu durante a Onda Rosa?

Este artigo dedica-se à face visível da ideologia neoliberal na política da América Latina6. Preocupa-se com o sentido ideológico da política econômica, isso é, com a apropriação de discursos e proposições de política econômica como instrumentos na disputa eleitoral. Evans e Sewell (2012) observam que o neoliberalismo possui uma dimensão de ideologia política, mas também de teoria econômica, de paradigma para política pública e de imaginário social. Algumas relações com a teoria econômica, enquanto base para a investigação, são reportadas na próxima seção. Entretanto, o foco da investigação é restrito na dimensão político-ideológica do neoliberalismo.

O corpo de pesquisa é composto pelos documentos programáticos (programas, planos, plataformas de governo) das candidaturas presidenciais lançadas entre 1999 e 2015. A partir de uma estratégia de análise de conteúdo, esquadrinha nos programas de governo a presença de noções que compõem o cerne do CW - espécie de manifesto programático do neoliberalismo. Portanto, a definição operacional de neoliberalismo aqui é dada pelo conceito de CW e nos termos das regras que o compõem.

A pesquisa envolve 13 países da América Latina, em um total de 47 eleições presidenciais entre 1999 e 2015. Foram analisados 94 programas de governo eleitorais, o que corresponde a igual número de candidaturas à presidência das nações latinoamericanas. Os países analisados são: Argentina, Bolívia, Brasil, Chile, Colômbia, Costa Rica, El Salvador, Equador, México, Panamá, Peru, Uruguai e Venezuela. O fator de seleção

\footnotetext{
6 Os partidos políticos ou o ambiente das eleições presidenciais não são os únicos locais de criação e disseminação de proposições ligadas ao neoliberalismo na América Latina, devendo ser ressaltado o papel de organizações da sociedade civil voltadas para essa finalidade (Gros, 2004; Fischer e Plehwe, 2013).
} 
foi a disponibilidade dos programas de governo dos dois principais candidatos em pelo menos três eleições consecutivas ${ }^{7}$. Foram incluídos todos os programas de governo dos candidatos eleitos e dos segundos colocados, em um total de três ou quatro eleições por país ocorridas no período de estudo.

A primeira seção, "O neoliberalismo nos programas de governo: aspectos teóricos, estratégia de análise de conteúdo e operacionalização das variáveis", apresenta os fundamentos teóricos da compreensão sobre as categorias discursivas adotadas para identificar a adesão dos programas ao ideário neoliberal (operacionalização das variáveis) e esboça a estratégia metodológica de análise de conteúdo. Essa estratégia é reportada em outros trabalhos (Oliveira, 2015, 2016a).

A segunda seção, "Existiu uma Onda Rosa na América Latina?", apresenta uma análise gráfica do comportamento ideológico das duas principais candidaturas presidenciais nos 13 países estudados. Realiza uma análise descritiva dos dados e busca uma definição mínima e consistente para a Onda Rosa. A terceira seção, "As regras do Consenso de Washington durante a Onda Rosa", mostra a presença, manutenção e transformações da ideologia neoliberal. Ao abrir o conceito de neoliberalismo nas regras do CW, é possível reparar como seu conteúdo ideológico mudou ao longo do período. A quarta seção, "Adesão ao Consenso de Washington: a análise de clusters e a versão mitigada (neoliberalismo do tripé macroeconômico)", realiza uma análise de clusters e identifica três agrupamentos: o dos programas de governo com presença abrangente das regras do $\mathrm{CW}$; o dos programas que rejeitam sistematicamente o neoliberalismo; e um agrupamento intermediário, cujo centro de aproximação com o neoliberalismo restringe-se à visão do tripé macroeconômico. Esse último grupo reúne programas que possuem elevada presença de certas regras do CW (câmbio flutuante, metas de inflação e de metas de superávit primário), mas rejeitam em grande medida suas demais disposições.

Na quinta seção, "Neoliberalismo e o debate sobre as duas esquerdas na Onda Rosa", o artigo apresenta algumas considerações sobre o debate da classificação das experiências estudadas. A investigação centrada no uso e na recusa do CW como elemento ideológico característico da América Latina recente permite um olhar complexo sobre questões por vezes tratadas como similares ou a partir de premissas normativas. 0 neoliberalismo atravessou a Onda Rosa da América Latina como elemento da identidade dos partidos que Ihe fizeram oposição, mas, também, em certa medida, como parte do conteúdo das bases programáticas dos próprios presidentes "pós-neoliberais". Estudar sua persistência ao longo desse período ajuda a compreender como, atualmente, o

\footnotetext{
${ }^{7}$ A pesquisa por programas de governo ocorreu em repositórios digitais de órgãos eleitorais, sites na internet de partidos políticos ou candidaturas e em veículos de imprensa. A eleição excepcional de 2013 na Venezuela, ocorrida em decorrência do falecimento de Hugo Chávez, não foi considerada já que os candidatos apresentaram os mesmos programas do pleito anterior. Os dados brutos utilizados estão organizados no Banco de Asserções Programáticas (BAP), disponível para download, que também informa as referências bibliográficas dos documentos utilizados e os partidos patrocinadores de cada candidatura (Oliveira, 2016b).
} 
neoliberalismo pôde voltar a disputar o espectro central da discussão política e a viabilizarse como opção das forças que protagonizam a tomada de decisão nos países da América Latina ${ }^{8}$.

\section{O neoliberalismo nos programas de governo: aspectos teóricos, estratégia de análise de conteúdo e operacionalização das variáveis}

A análise de conteúdo (Henry e Moscovici, 1968; Lasswell, 1982; Bardin, 1995) é uma estratégia adotada para estruturar a leitura de documentos ou outros registros, de maneira a organizar, padronizar e quantificar a apreensão de significados. Seu objetivo principal é capturar, para além do conteúdo formal da comunicação, elementos identificadores do fenômeno discursivo associado à sua autoria. Em suma, engloba um desenho estratégico que visa alcançar os valores presentes no momento em que o(s) autor(es) se expressam.

No que concerne à comunicação política e, especialmente, às eleições, a análise de conteúdo dos programas de governo partidários é uma ferramenta usual. Normalmente os candidatos apresentam programas de governo formais, redigidos e documentados em um volume ou em um conjunto de volumes ou fascículos. Os programas também são apresentados como documentos virtuais, páginas disponíveis na internet. Em algumas circunstâncias, no lugar de um programa de governo formal, podem ser encontrados pronunciamentos dos candidatos à imprensa.

Em todos os casos, trata-se de manifestações políticas com uma intenção propriamente eleitoral. Se os programas não visam necessariamente conquistar votos (como um panfleto de campanha), eles fornecem os contornos nos quais o candidato opera em relação aos seus oponentes e fixa os termos do debate prospectivo. Seu conteúdo é objeto de crítica pelas candidaturas competidoras e pela mídia, podendo responsabilizar o candidato eleitoralmente.

Seus autores respondem, portanto, às pressões provenientes do eleitorado (bem como de apoiadores e financiadores). Essa característica não precisa ser compreendida como fraude das reais intenções ou valores dos autores, dispostos a mentir para conquistar votos ou apoio. Interesses, opiniões, cálculo político, confundem-se na dimensão ideológica do programa de governo. Isso ocorre necessariamente pela razão de que a condição da realização de um programa é a vitória eleitoral. É justamente o aspecto relacional do discurso eleitoral inserido nos programas de governo que permite o acesso ao fenômeno ideológico, isto é, ao uso de ideias como armas na disputa do poder político.

8 O banco de dados utilizado neste artigo está disponibilizado no site do Cesop (<cesop.unicamp.br), na seção Revista Opinião Pública, ao final da página referente a este artigo. 
O que a análise de conteúdo dos programas de governo é capaz de revelar não é necessariamente seu conteúdo prospectivo ou promessas - o que pode ser pesquisado enquanto congruência entre o conteúdo do programa e a política pública ${ }^{9}$. Em primeiro plano, é uma forma de apreender e comparar como as candidaturas se organizam uma em relação às outras e em face da visão do eleitorado que municia a estratégia de campanha. Tal descrição pode parecer artificial, e muitas vezes os programas contêm uma boa dose de artificialidade. Mais uma vez, entretanto, deve-se ressalvar que os programas de governo não são peças autônomas da realidade política. Sua capacidade de ter incidência política depende de estar conectado à trajetória pessoal dos candidatos, à história dos partidos políticos que apoiam a candidatura e dos governos aos quais fazem oposição ou aos quais se alinham, às políticas públicas adotadas por esses governos, aos grupos sociais organizados que podem apoiar ou rechaçar a candidatura, aos sentimentos mais difusos existentes entre os eleitores (sejam eles orientados ideologicamente ou não).

Por essas razões, a análise de conteúdo dos programas de governo nas candidaturas presidenciais é uma estratégia adequada para revelar os valores que informam o comportamento ideológico das candidaturas e, indiretamente, dos partidos relacionados. Permite abrir uma entrada para o fenômeno da autoria, para estudar comparativamente a adesão ou o espaço que um determinado tema de cognição política possui no posicionamento da candidatura.

A estratégia de análise de conteúdo adotada na presente pesquisa é baseada na presença ou ausência de asserções programáticas do corpo do programa de governo analisado. Por asserção, compreende-se um fragmento de texto que expressamente disponha (a) um posicionamento positivo em relação ao conteúdo especificado e/ou (b) a intenção programática de que, após vencer as eleições, o presidente eleito atuará para que um posicionamento seja traduzido em política pública.

O conteúdo a ser mensurado diz respeito à adesão às proposições típicas do neoliberalismo, a partir das diretrizes do CW. Essa definição limitada é oportuna do ponto de vista operacional da análise empírica e justificável a partir do processo histórico de construção de uma ideologia neoliberal no contexto político-eleitoral da América Latina (ponto explorado em seguida). Salienta-se que, embora a definição de neoliberalismo ancorada no CW não avance sobre um fenômeno que recebe interpretações complexas e polivalentes na teoria sociológica (Andrade, 2019), ela evita a crítica de um uso excessivamente elástico ou impreciso do termo em análises empíricas - como reparado por Fernandes e Borges (2008).

\footnotetext{
${ }^{9} \mathrm{O}$ recorte da presente pesquisa está restrito às plataformas das candidaturas e, portanto, ao neoliberalismo enquanto ideologia programática. Para uma discussão recente sobre diferentes formas de investigar a congruência política, inclusive com o uso de programas de governo, pode-se consultar Carreirão (2015).
} 
O termo "Consenso de Washington" foi cunhado por Williamson $(1990,2008)$ no ano de 1989, em referência às dez políticas que deveriam ser adotadas pelos países da América Latina na visão consensual dos organismos financiadores do governo dos Estados Unidos e organizações multilaterais - Banco Mundial, Fundo Monetário Internacional. O fundamento do CW, conforme Williamsom (1990, p. 1), é "que os objetivos econômicos convencionais de crescimento, inflação baixa, viabilidade da balança de pagamentos e justa distribuição de renda devem determinar a utilização dos instrumentos de política [econômica]"10.

O autor apresenta as dez propostas no contexto de crítica às estratégias de crescimento adotadas no subcontinente a partir dos anos de 1950 (desenvolvimentismo, substituição de importação), em favor do que seriam as práticas frequentes e relacionadas ao sucesso dos países desenvolvidos do Ocidente. Como faz questão de reparar em textos posteriores (Williamson, 1993, 2008), as medidas do CW não estariam ligadas às noções neoliberais dos governos Thatcher e Reagan - monetarismo, economia supply-side e governo mínimo.

As políticas do CW foram reinterpretadas ao longo do tempo, tanto a partir de aportes por especialistas (tecnocratas e acadêmicos) como em relação às idiossincrasias nacionais relacionadas à implantação das normas (Marangos, 2009). Como aponta Stiglitz (2008), o termo Consenso de Washington distanciou-se do uso dado por Williamson para referir-se mais genericamente ao conjunto de propostas focadas em privatização, liberalização e estabilidade de preços, passando a ser usado em uma conotação relativamente descolada da teoria econômica:

Para a maioria das pessoas, o Consenso de Washington representa um conjunto de políticas baseado em uma forte crença - mais forte do que o justificável pela teoria econômica ou pela experiência histórica - na liberalização do mercado e no objetivo de reduzir ou mesmo minimizar o papel do governo (Stiglitz, 2008, p. 41) ${ }^{11}$.

Tangenciando sua utilização como recurso político-ideológico, Naim (2000) observa que o CW desempenhou um papel relevante para simplificar e organizar a complexa realidade dos países "em desenvolvimento" e prescrever um plano de ação para a política econômica não apenas para a América Latina, mas também para países do leste europeu, em face da dissolução da União Soviética. Distanciando-se das intenções originais de Williamson, Naim aponta a razão pela qual o nome foi popularizado e, no que tange ao rigor acadêmico, corrompido:

\footnotetext{
10 No original: "that the standard economic objectives of growth, low inflation, a viable balance of payments, and an equitable income distribution should determine the disposition of such policy instruments".

${ }^{11}$ No original: "To most people, the Washington Consensus represents a set of policies predicated upon a strong faith - stronger than warranted either by economic theory or historical experience - in unfettered markets and aimed at reducing, or even minimizing, the role of government".
} 
Porque, na época, [o termo Consenso de Washington] preenchia um vácuo ideológico e era relativamente simples para os políticos entenderem e usarem em seus discursos. Também deu aos ministros um plano de ação prático com objetivos específicos; tinha o aval de instituições e indivíduos de prestígio e, por último, mas não menos importante, tinha dinheiro. A adoção do Consenso de Washington, prometia-se (e se esperava), traria toneladas de dinheiro estrangeiro. O FMI e o Banco Mundial abririam seus cofres. Os investidores estrangeiros, ansiosos por se beneficiar da prosperidade que as novas políticas trariam para os países em reforma, também contribuiriam para a bonança financeira (Naim, 2000, p. 508) ${ }^{12}$.

Enquanto Stiglitz e Naim apontam para uma apropriação política do CW, como se ele sofresse uma metamorfose entre teoria econômica e ideologia, Bresser-Pereira (2006) ressalta que em certo sentido essa diferenciação pode ser desconsiderada. $O$ autor identifica dois momentos do CW. O inicial, tal como apresentado por Williamson, enquanto resposta de política econômica para a crise da dívida; e o decorrente, em que o CW passa a ser compreendido como uma estratégia de desenvolvimento. No entanto, ambas as versões do consenso estariam unidas enquanto partes de uma mesma onda ideológica (que denomina ortodoxia convencional) com início nos Estados Unidos na década de 1970. De forma mais direta, Bresser-Pereira (2006, p. 17) salienta: "O Consenso de Washington é, na verdade, a forma que a ideologia neoliberal e globalista assumiu, efetivamente, no plano das políticas econômicas recomendadas aos países em desenvolvimento".

Observa-se que as fronteiras pouco claras entre teoria econômica e ideologia representam um desafio para a análise do uso político do CW. Nesse sentido, a estratégia de análise de conteúdo precisa transitar entre o conteúdo formal do CW e sua apropriação político-ideológico nos programas de governo das candidaturas presidenciais. Para dar conta do desafio, a operacionalização das regras do CW seguiu alguns procedimentos. Inicialmente, partiu-se de uma aproximação à noção original que Williamson emprestou às dez regras. O segundo passo foi retrabalhar cada regra de acordo com a literatura ${ }^{13}$ que trata da incorporação do CW na América Latina (reinterpretação). O terceiro passo foi selecionar no Banco de Asserções Programáticas (BAP) aquelas variáveis (asserções) que dialogam com o conteúdo da regra do $\mathrm{CW}$ em questão. Algumas regras do $\mathrm{CW}$ foram

\footnotetext{
12 No original: "Because, at the time, it filled an ideological vacuum and it was relatively simple for politicians to understand and use in speeches. It also gave ministers a practical action plan with specific goals; it had the endorsement of prestigious institutions and individuals and, last but not least, it had the ring of money. The adoption of the Washington Consensus, it was promised (and expected), would bring tons of foreign money. The IMF and the World Bank would open their coffers. Foreign investors, eager to benefit from the prosperity that the new policies would bring to reforming countries would also contribute to the financial bonanza".

13 Os trabalhos consultados foram os seguintes: Sader e Gentili (1998), Rodrik (2006), Garretón e outros (2007), Marangos (2009), Naim (2000), Bresser-Pereira e Theuer (2012) e Ruckert, MacDonald e Proulx (2017).
} 
operacionalizadas a partir de duas ou mais asserções programáticas do BAP. Nesse caso, a presença de qualquer asserção dentre as listadas foi computada como adesão à regra do CW. Portanto, objetivamente, o que a investigação constata nos programas de governo é a presença ou a ausência dos conceitos operacionalizados descritos abaixo.

Além do decálogo de Williamson, uma $11^{\text {a }}$ regra foi incluída. Trata-se da proposição de que a política econômica deve dedicar-se principalmente ao controle da inflação. Essa regra apreende um elemento finalístico do $\mathrm{CW}$ que dialoga com a adesão aos valores do neoliberalismo, conforme inferido por Stiglitz, tanto no contexto da hiperinflação dos anos 1980 na América Latina quanto no da estagflação na Europa Ocidental.

Regra 1 - Disciplina Fiscal. Visão original: não permitir, como cláusula geral, que o déficit fiscal anual atinja $1 \%$ ou $2 \%$ do Produto Interno Bruto. Reinterpretação: redução, eliminação do déficit fiscal. Operacionalização: proposta de/referência positiva à redução ou limitação do déficit orçamentário (variável número 41 do BAP).

Regra 2 - Redução do Gasto Público. Visão original: prioridades do gasto público. Reverter o gasto público, especialmente de subsídios indiscriminados para políticas de saúde e educação que beneficiem os mais pobres e políticas de investimento. Reinterpretação: promoção do ajuste fiscal por meio do corte de gastos públicos. Operacionalização: proposta de/referência positiva ao controle ou diminuição do gasto público (variável número 50 do BAP).

Regra 3 - Reforma Tributária. Visão original: preferência por tributos com incidência mais ampla e menor taxa. Reinterpretação: diminuição da carga tributária sobre a atividade econômica e a riqueza. Operacionalização: proposta de/referência positiva à diminuição de tributos que incidem sobre a produção ou o consumo (variável número 10 do BAP); ou proposta de/referência positiva à diminuição de tributos que incidem sobre o capital (variável número 11 do BAP).

Regra 4 - Autonomia do Banco Central. Visão original: liberalização financeira. Levantamento de interferências governamentais, para que as taxas de juros sejam livremente decididas pelo mercado financeiro. Reinterpretação: desregulamentação do mercado financeiro, autonomia do Banco Central. Operacionalização: proposta de/referência positiva à autonomia do Banco Central (variável número 44 do BAP).

Regra 5 - Câmbio de Mercado. Visão original: taxa de câmbio de mercado. Assegurar a vigência de uma taxa de câmbio competitiva. Reinterpretação: livre flutuação da taxa de câmbio. Operacionalização: proposta de/referência positiva à não intervenção na taxa de câmbio ou moeda forte (variável número 47 do BAP).

Regra 6 - Abertura Comercial. Visão original: liberalização da política comercial. A partir do ideal de livre mercado, evitar as barreiras alfandegárias e definir limites para taxação de importação (10\% ou 20\%). Reinterpretação: abertura comercial, firmação de acordos de livre comércio. Operacionalização: proposta de/referência positiva à diminuição 
de barreiras comerciais com os Estados Unidos ou adesão ao Tratado Norte-Americano de Livre Comércio (Nafta), Tratado de Livre Comércio entre Estados Unidos, América Central e República Dominicana (Cafta) ou Área de Livre Comércio das Américas (Alca) (variável número 2 do BAP); ou proposta de/referência positiva à economia de livre mercado ou à eliminação de restrições ao comércio entre os países por meio de tarifas e cotas (variável número 49 do BAP).

Regra 7 - Investimento Externo Direto. Visão original: liberalização do investimento externo direto. Abolição dos mecanismos que barram ou constrangem o investimento financeiro externo. Reinterpretação: abertura para o investimento externo direto. Operacionalização: proposta de/referência positiva ao investimento externo direto (variável número 48 do BAP).

Regra 8 - Privatização. Visão original: privatização das empresas econômicas estatais. Reinterpretação: privatização de empresas e serviços públicos. Operacionalização: proposta de/referência positiva à privatização (variável número 12 do $\mathrm{BAP})$.

Regra 9 - Desregulamentação. Visão original: desregulamentação das relações econômicas. Diminuição das exigências burocráticas para as empresas se instalarem e fazerem negócios. Reinterpretação: desregulamentação das leis trabalhistas, desburocratização. Operacionalização: proposta de/referência positiva à busca de eficiência administrativa, eficiência do governo ou contra a burocracia com viés favorável ao desenvolvimento do mercado (variável número 18 do BAP); ou proposta de/referência positiva à desregulamentação, flexibilização ou livre negociação nas relações de trabalho (variável número 30 do BAP).

Regra 10 - Direito de Propriedade. Visão original: assegurar direitos de propriedade. Dotar os agentes econômicos de formas de garantir a proteção da propriedade a custos acessíveis. Reinterpretação: proteção da propriedade privada, inclusive intelectual. Operacionalização: proposta de/referência positiva à garantia dos direitos de propriedade (variável número 22 do BAP).

Regra 11 - Estabilidade de Preços. Visão original: estabilidade de preços como um dos objetivos da política econômica. Reinterpretação: estabilidade de preços como função precípua da política econômica. Operacionalização: proposta de/referência positiva ao controle da inflação como meta da política econômica (variável número 43 do BAP).

A partir das 11 regras do CW descritas, foi calculado um indicador global da adesão de cada programa de governo ao neoliberalismo, chamado "CW - Neoliberalismo". Seu cálculo é a simples média aritmética do conjunto de 11 regras $\left(\frac{1}{11} \sum_{i-1}^{11} \operatorname{Regra}_{i}\right)$. O indicador possui a variação entre 0 , nenhuma presença de regra no programa de governo, e 1 , presença de todas as regras no programa de governo. $O$ indicador pode ser utilizado como marcador sintético do grau de adesão ao neoliberalismo manifestado no programa de governo de uma candidatura presidencial ou de um grupo de candidaturas. 


\section{Existiu uma Onda Rosa na América Latina?}

Esta seção busca averiguar se, a partir da análise dos programas de governo presidenciais, é possível observar a existência do fenômeno descrito como Onda Rosa. O foco encontra-se no posicionamento ideológico das candidaturas vitoriosas e derrotadas nas eleições presidenciais.

O Quadro 1 mostra quantas das eleições analisadas foram vencidas pela candidatura com programa de governo menos neoliberal, em cada país estudado. Também fornece o valor médio do indicador CW - Neoliberalismo por país, discriminando os valores médios dos programas de candidatos presidenciais eleitos e dos programas dos candidatos derrotados (segundos colocados). Observando-se a diferença entre o CW - Neoliberalismo dos candidatos eleitos e dos derrotados, verifica-se em quais países existe um resultado negativo - isto é, preferência pelos candidatos com programas de governo menos aderentes ao neoliberalismo.

\section{Quadro 1}

Eleições e indicador CW - Neoliberalismo (médio) por país, por programa de governo de candidato eleito e de candidato derrotado

(América Latina, 1999-2015)

\begin{tabular}{|l|c|c|c|c|c|}
\hline & \multicolumn{2}{|c|}{ Eleições } & \multicolumn{2}{c|}{ CW - Neoliberalismo (média) } \\
\cline { 2 - 6 } & Analisadas & $\begin{array}{c}\text { Vitórias } \\
\text { do menos } \\
\text { neoliberal }\end{array}$ & $\begin{array}{c}\text { Programas } \\
\text { eleitos }\end{array}$ & $\begin{array}{c}\text { Programas } \\
\text { derrotados }\end{array}$ & $\begin{array}{c}\text { Diferença } \\
\text { eleitos x } \\
\text { derrotados }\end{array}$ \\
\hline Argentina & 4 & 3 & 0,14 & 0,32 & $-18 \%$ \\
\hline Bolívia & 4 & 2 & 0,18 & 0,27 & $-9 \%$ \\
\hline Brasil & 4 & 4 & 0,36 & 0,71 & $-35 \%$ \\
\hline Chile & 4 & 3 & 0,64 & 0,59 & $4 \%$ \\
\hline Colômbia & 4 & 1 & 0,36 & 0,27 & $9 \%$ \\
\hline Costa Rica & 4 & 2 & 0,45 & 0,38 & $7 \%$ \\
\hline El Salvador & 3 & 1 & 0,55 & 0,46 & $9 \%$ \\
\hline Equador & 4 & 3 & 0,30 & 0,38 & $-9 \%$ \\
\hline México & 3 & 0 & 0,55 & 0,42 & $13 \%$ \\
\hline Panamá & 3 & 0 & 0,33 & 0,27 & $6 \%$ \\
\hline Peru & 3 & 0 & 0,55 & 0,42 & $13 \%$ \\
\hline Uruguai & 4 & 3 & 0,39 & 0,46 & $-7 \%$ \\
\hline Venezuela & 3 & 3 & 0,21 & 0,73 & $-51 \%$ \\
\hline Todos os casos & $\mathbf{4 7}$ & $\mathbf{2 6}$ & $\mathbf{0 , 3 8}$ & $\mathbf{0 , 4 3}$ & $-\mathbf{5 \%}$ \\
\hline
\end{tabular}

Fonte: Elaborado pelo autor com base em Oliveira, 2016a.

O Quadro 1 indica que os programas menos neoliberais (em comparação com os segundos colocados) foram vitoriosos em 55\% das eleições analisadas. Considerando 
todos os 94 programas estudados, verifica-se que existe uma pequena desproporção (da ordem de $5 \%$ ) contrária às regras do CW. São evidências pouco animadoras para identificar a Onda Rosa.

Em seis países, os candidatos menos neoliberais venceram a maioria das eleições analisadas: Argentina, Brasil, Chile, Equador, Uruguai e Venezuela. Na Bolívia, o menos neoliberal venceu duas de quatro eleições. Em todos, exceto no Chile, o valor médio do indicador CW - Neoliberalismo foi menor entre os candidatos eleitos do que entre os derrotados. Chama atenção, entretanto, a baixa diferença entre os programas de governo dos candidatos vencedores e derrotados na Bolívia (9\%), no Equador (9\%) e no Uruguai (7\%). Nos seis países restantes - Colômbia, Costa Rica, El Salvador, México, Panamá e Peru -, observa-se uma média do indicador CW - Neoliberalismo positiva, ou seja, com maior presença do neoliberalismo entre os eleitos do que entre os derrotados. México, Panamá e Peru não elegeram o menos neoliberal em nenhuma oportunidade, enquanto El Salvador e Colômbia em apenas uma das eleições analisadas.

Se a Onda Rosa é caracterizada pela vitória de presidentes com plataformas programáticas que rejeitam o neoliberalismo em seus contextos nacionais, conforme as duas análises do Quadro 1, então esse é um fenômeno observado em seis dos 13 países estudados (Argentina, Bolívia, Brasil, Equador, Uruguai e Venezuela). Para buscar uma definição mais precisa para a Onda Rosa, a Figura 1 abre as informações no tempo: apresenta a distribuição dos programas por desempenho no indicador CW Neoliberalismo, por país, no período 1999-2015. Indica, em azul, os programas de governo das candidaturas vitoriosas e, em vermelho, as candidaturas derrotadas nas eleições presidenciais.

Na Argentina, a sequência de eleições vencidas pela Frente para a Vitória (FPV) (2003-2011) apresentou uma trajetória de abandono do CW, com queda no indicador. Essa trajetória foi revertida, por diferença marginal, com a vitória da Proposta Republicana (PRO), em 2015. Considerando as duas candidaturas com melhor desempenho nas quatro mais recentes eleições argentinas, percebe-se que tanto a FPV quanto seus opositores convergiram para uma agenda distante do CW.

No mesmo sentido, as três últimas eleições presidenciais na Bolívia levaram à escolha do candidato do Movimento ao Socialismo (MAS), com baixa e decrescente adesão ao CW. Nesse país - assim como na Argentina -, os partidos de oposição apresentaram programas com pouca presença das regras do CW. A exceção é a candidatura oposicionista e derrotada oferecida pelo partido Poder Democrático Social (Podemos) em 2005. 
Figura 1 Indicador CW - Neoliberalismo por país, ano da eleição e resultado eleitoral
(América Latina, 1999-2015)

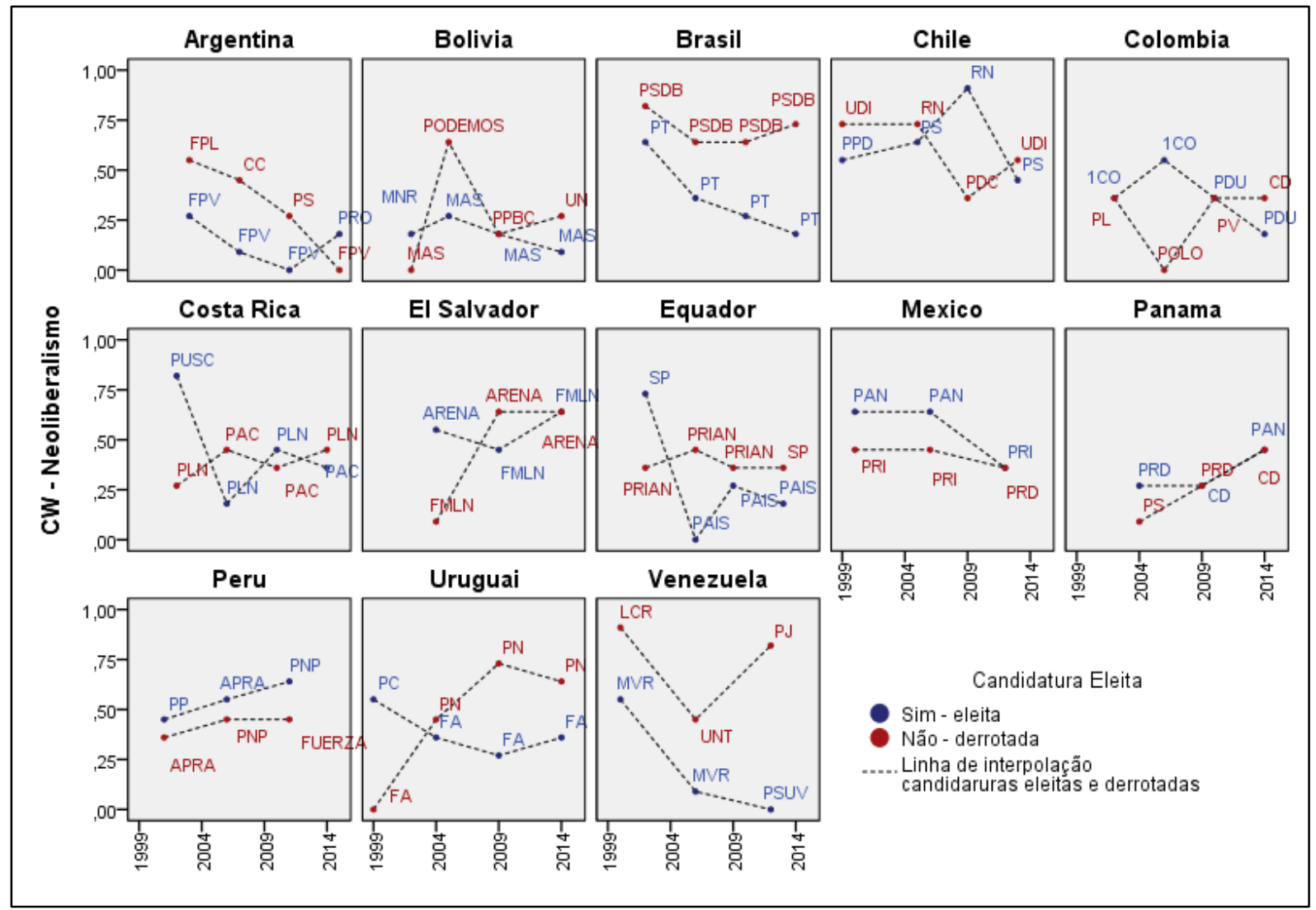

Fonte: Elaborada pelo autor com base em Oliveira, 2016a.

O comportamento do Partido dos Trabalhadores (PT) no Brasil foi semelhante ao observado na FPV e no MAS, com abandono do neoliberalismo após a eleição vitoriosa de 2002. Embora o PT tenha alçado a presidência em 2002 com um programa implicado em sete das 11 regras do CW, na última eleição analisada - 2014 - apenas duas eram manejadas (Desregulamentação e Estabilidade de Preços). Principal força de oposição eleitoral, o Partido da Social Democracia Brasileira (PSDB) preservou uma diferença importante em relação ao PT, com maior adesão ao CW (diferentemente das candidaturas de oposição na Argentina e na Bolívia).

O Chile é o país com maior presença do CW, conforme destaca o Quadro 1. Podese observar na Figura 1 como os programas permanecem na parte intermediária e superior do quadro. Em seu programa de governo, a candidatura bem-sucedida da Renovação Nacional (RN), em 2009, indicava adesão a todas as regras do CW, com exceção de Privatizações. Em que pese serem menos favoráveis ao $\mathrm{CW}$ do que seus oponentes, tratar 
das candidaturas dos partidos que compuseram a Concertação de Partidos pela Democracia no Chile é uma questão complexa, considerada adiante.

A Colômbia não é associada à Onda Rosa, mas chama atenção que os programas de governo das candidaturas presidenciais estudadas no país possuem baixa presença do neoliberalismo. O fato de que o principal partido contrário ao neoliberalismo do país - o Polo Democrático Alternativo (Polo) - entrou na pesquisa apenas em 2002 não impediu que o CW - Neoliberalismo médio da Colômbia ficasse significativamente inferior ao da América Latina (Quadro 1). O parapartido Primeiro Colômbia (1CO) (do ex-presidente Álvaro Uribe, vencedor em 2002 e 2006) foi sucedido pelo Partido Social de Unidade Nacional (PDU), em 2010 e 2014. A trajetória mostra uma queda da importância do CW nos programas de governo dos eleitos entre 2006 e 2014; mas, considerando as principais candidaturas oposicionistas, a agenda neoliberal não parece ser um foco de distinção política. Em 2002 e em 2010, as duas principais candidaturas aderiram ao mesmo número de regras: quatro.

Na Costa Rica, após a vitória, em 2002, de uma candidatura claramente vinculada ao neoliberalismo (Partido Unidade Social Cristã - PUSC), a eleição de 2006 marca um recuo com a vitória do Partido de Libertação Nacional (PLN). Após 2006, PLN e Partido de Ação Cidadã (PAC) passaram a disputar em um campo semelhante em relação ao nível de aderência ao CW.

Em El Salvador, quando a Frente Farabundo Martí para a Libertação Nacional (FMLN) obteve a vitória em 2009, o país se aproxima da Onda Rosa. Entretanto, se o programa da FMLN em 2004 era claramente contrastante com o da Aliança Republicana Nacionalista (Arena) pela expressa rejeição do neoliberalismo, nas eleições subsequentes a diferença ficou menos marcada. Nas últimas eleições analisadas (2014), os dois partidos apresentaram o mesmo número de ênfases do CW.

No Equador, a eleição de 2006 apresenta uma mudança radical. Se a candidatura do partido Sociedade Patriótica 21 de Janeiro (SP) em 2002 apresentava oito das 11 regras do CW, o Movimento Pátria Altiva e Soberana (Pais), eleito em 2006, o rejeitava completamente. Mesmo que nas reeleições subsequentes o PAIS incluísse algumas regras do CW em seus programas de governo, as opções derrotadas vinculavam-se mais claramente aos valores do neoliberalismo.

O programa de governo do principal partido mexicano antagônico ao neoliberalismo, o Partido da Revolução Democrática (PRD), foi incluído na pesquisa apenas na eleição de 2012 (em 2000 e 2006 permaneceu em terceiro lugar). O Partido Ação Nacional (PAN), vitorioso nas duas primeiras eleições analisadas, é o de maior adesão ao CW (sete ênfases em cada programa de governo). Quando da vitória do Partido da Revolução Institucional (PRI) em 2012, seu programa possuía o mesmo número de ênfases do CW do que o PRD. Verifica-se, portanto, uma inflexão para o quadrante inferior (maioria das propostas do CW ausentes). 
No Panamá, nenhum dos programas analisados apresenta mais do que cinco regras do CW. A agenda do neoliberalismo não parece ser um fator de mobilização políticoprogramática no país, tanto que nas duas últimas eleições as principais candidaturas (Câmbio Democrático - CD; Partido Revolucionário Democrático - PRD; e Partido Panamenho - PAN) apresentaram o mesmo número de ênfases do CW em seus programas de governo: três em 2009, cinco em 2014.

Como já revelado pelo Quadro 1, nas três eleições do Peru as candidaturas com maior número de regras do CW saíram-se vitoriosas. Peru Possível (PP), Ação Popular (Apra) e Partido Nacionalista Peruano (PNP) apresentaram, respectivamente, cinco, seis e sete regras do CW. Não obstante, as segundas candidaturas em todos os pleitos não divergiram de maneira muito significativa das vencedoras quanto à aderência ao neoliberalismo. Essa informação permite colocar em avaliação a percepção de que as candidaturas do PNP, capitaneadas por Ollanta Humala, fariam parte da Onda Rosa.

No Uruguai, a primeira candidatura analisada da Frente Ampla (FA), em 1999, rejeitava completamente o CW. Após essa eleição, vencida pelo Partido Colorado (PC), a FA ganhou em 2004, 2009 e 2014 apresentando programas de governo com 3 ou 4 regras do CW. O principal partido opositor - Partido Nacional (PN) - manteve, durante o período, vinculação muito mais clara com os valores do neoliberalismo. Nesse sentido, a oposição uruguaia recente se assemelha mais com a brasileira do que com a argentina.

Nas três eleições apresentadas, os cidadãos da Venezuela elegeram Hugo Chávez presidente da República, seja pelo Movimento V República (MVR), em 2000 e 2006, ou por seu sucessor, o Partido Socialista Unido da Venezuela (PSUV), em 2012. Em conjunto, essas agremiações apresentam um movimento de abandono das regras do CW. Se, em 2000, o MVR chegou a apresentar seis regras do CW em seu programa de governo, o PSUV as rejeitou completamente. As opções mantidas na oposição permaneceram ligadas aos valores do neoliberalismo, em contraste aos programas vitoriosos - com relativa ponderação da candidatura de 2006, Um Novo Tempo (UNT).

Os grupos políticos que impulsionaram a Onda Rosa nos seis países destacados pelo Quadro 1 (Argentina, Bolívia, Brasil, Equador, Uruguai e Venezuela) apresentam dois padrões de comportamento em face da presença de regras do $\mathrm{CW}$ em seus programas de governo presidenciais. Em quatro casos - a argentina FPV, o boliviano MAS, o brasileiro PT e o venezuelano MVR/PSUV -, após as primeiras eleições presidenciais analisadas, iniciaram um movimento de abandono das regras do CW. Em dois casos, PT e MVR, esse movimento é especialmente saliente, considerando uma presença inicial de, respectivamente, sete e seis regras. Em sentido inverso, no Equador, o PAIS passou a apresentar um número maior de regras nas eleições posteriores a sua primeira vitória. No Uruguai, a FA manteve o espaço do CW em seus programas de governo entre 2004 e 2014.

A análise gráfica das trajetórias ajuda a pensar sobre os casos da Costa Rica, de El Salvador e do Peru. Nos dois primeiros, PLN e FMLN de fato assumem a presidência com 
programas de governo menos neoliberais do que seus opositores principais. Contudo, em ambos os casos, nas eleições subsequentes apresentam maior (PLN) ou igual (FMLN) aderência ao CW em relação a seus principais opositores. No Peru, embora o PNP tenha concorrido como opção menos liberal em 2006, na eleição vitoriosa de 2011 apresentava maior presença de regras do CW do que a candidatura da Força Popular (Fuerza). Todos os três (PLN, FMLN e PNP), ademais, mantiveram uma presença do CW em seus programas significativamente superior às observadas no FPV, no PT, no MAS ou no MVR/PSUV.

A partir dessas observações, é possível definir um conceito mínimo para a Onda Rosa que reporte: (1) um fenômeno em âmbito nacional, não apenas uma eleição isolada; (2) coerência com uma dimensão político-ideológica contrária ao neoliberalismo no contexto nacional; (3) relativa autonomia em relação a partidos/candidaturas, ou seja, prioridade para o conteúdo ideológico (menor adesão ao neoliberalismo) em detrimento da permanência da força política atuante. Foram definidos os seguintes critérios como conceito mínimo da Onda Rosa, em que concerne ao neoliberalismo:

a) vitória eleitoral de candidaturas que apresentam programas de governo com menor presença do $\mathrm{CW}$ em detrimento das alternativas eleitoralmente mais relevantes; e

b) ao menos uma vitória consecutiva da mesma candidatura ou do mesmo partido, desde que em face de alternativa com maior ou igual adesão ao CW; ou

c) vitória consecutiva de outra candidatura ou partido, desde que em face de alternativa com maior adesão ao CW.

Considerando esse conceito mínimo, a Onda Rosa seria observada nas seguintes eleições: Argentina, 2003, 2007 e 2011; Bolívia, 2005, 2009 e 2014; Brasil, 2002, 2006, 2010 e 2014; Chile, 1999 e 2005; El Salvador, 2009 e 2014; Equador, 2006, 2009 e 2013; Uruguai, 2004, 2009 e 2014; e Venezuela14, 2000, 2006 e 2012. A partir do conceito mínimo, observa-se uma tendência de eleição de presidentes menos associados ao neoliberalismo na América Latina a partir das eleições do PPD de 1999, do MVR de 2000 e do PT de 2002, embora possuíssem expressivo conteúdo programático do neoliberalismo. A partir da virada do século, entre 1999 e 2002, momento em que parece iniciar, a Onda Rosa ganha força e alcança um número crescente de países.

Se considerada a Concertação de Partidos pela Democracia (sequência de candidaturas PPD, PS, Partido Democrata Cristão - PDC) como unidade organizacional, a trajetória da Onda Rosa no Chile revela uma circunstância interessante. Com apenas quatro regras do CW, a candidatura do PDC de 2009 foi a menos neoliberal dentre as observadas no Chile, o que poderia colocar a Concertação em uma trajetória de

\footnotetext{
14 Ressalva-se que a primeira eleição de Hugo Chávez, do MVR da Venezuela, ocorrida no final de 1998, não foi incluída na pesquisa. Não foi possível obter o programa de governo da candidatura derrotada na eleição de 1998.
} 
afastamento do CW próxima à do FPV, do PT e do MVR/PSUV. Entretanto, a vitória da RN em 2009 - com um programa expressamente neoliberal - interrompeu a Onda Rosa chilena. Por fim, para que a Costa Rica fosse incluída na definição mínima na Onda Rosa, de forma coerentemente contrária ao neoliberalismo, após a vitória do PLN, em 2006, deveria ter ocorrido a vitória do PAC, em 2010 (o que ocorreu apenas em 2014).

\section{As regras do Consenso de Washington durante a Onda Rosa}

A Figura 2 mostra a presença de cada regra do CW nos programas de governo dos presidentes eleitos e nos dos candidatos que ficaram em segundo lugar, não eleitos, na América Latina, entre 2002 e 2015. A linha azul marca os programas vitoriosos, a vermelha, os derrotados. As linhas refletem o valor médio da presença do conjunto das regras do $\mathrm{CW}$ entre todos os casos analisados. Assim, o valor 1 indica que a respectiva regra é presente em todos (100\%) os programas de governo dos candidatos eleitos ou derrotados do ano indicado ou do intervalo até o próximo ciclo eleitoral.

O quadro da Figura 1, que apresenta o indicador CW - Neoliberalismo, consolida a posição de todos os países estudados (individualizados na Figura 1). Pode-se observar que, na marca do ano 2006, existe uma inflexão relevante da linha azul, indicando a queda do número de regras do $\mathrm{CW}$ nos programas de governo dos presidentes eleitos. Trata-se da eleição dos candidatos com programas de governo menos neoliberais na Costa Rica (PLN) e no Equador (PAIS), bem como do abandono do neoliberalismo no Brasil (PT) e na Venezuela (MVR).

A análise do desempenho das regras do $\mathrm{CW}$ permite observar quais foram abandonadas e quais permaneceram no cenário político. Permite, também, observar quais regras foram preservadas pelos partidos alijados do poder e quais foram incorporadas nos programas de governo dos candidatos eleitos.

A Regra 1 - Disciplina Fiscal permaneceu presente em metade ou mais dos programas, inclusive entre os candidatos eleitos. Nesse grupo, nota-se no ano de 2006 uma expressiva queda da preocupação com o déficit fiscal. Uma retomada do interesse pela Disciplina Fiscal ocorre em 2009, mais frágil entre as candidaturas eleitas do que entre as derrotadas. Salienta-se, de qualquer forma, que a regra da Disciplina Fiscal é uma das mais frequentes no panorama político-ideológico da América Latina, com uma presença em $66 \%$ dos programas analisados - inclusive todos os do Chile e do Peru. 
Figura 2

Regras do Consenso de Washington e CW - Neoliberalismo, por ano (América Latina, 2002-2015)

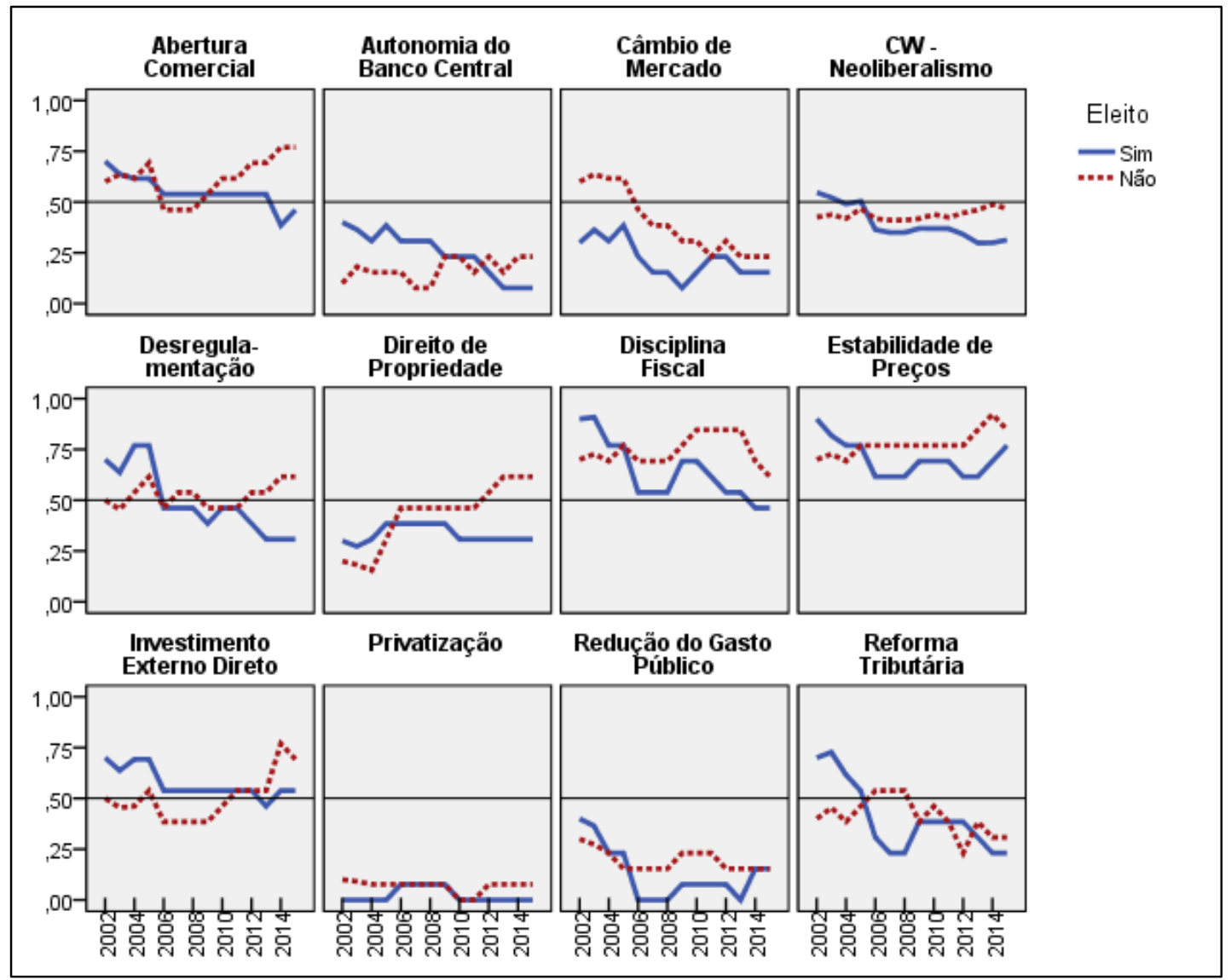

Fonte: Elaborada pelo autor com base em Oliveira, 2016a.

A Regra 2 - Redução do Gasto Público, em que pese o paralelismo com a Disciplina Fiscal, não possuiu o mesmo desempenho. Após ser eliminada dos programas vitoriosos com a Onda Rosa, no ano de 2006, continuou com uma participação muito marginal tanto entre os eleitos quanto entre os derrotados. Sublinha-se, contudo, que a impopular regra 2 foi mais frequente nos programas derrotados entre 2006 e 2014 (15\% dos programas). Apenas no Brasil e no Uruguai atinge $50 \%$ dos programas analisados, sendo inferior em todos os demais, inclusive com nenhuma contribuição na Argentina, Bolívia, Colômbia, Panamá e Venezuela.

Assim como as regras anteriores, a Regra 3 - Reforma Tributária também sofreu um revés importante durante os primeiros anos da Onda Rosa. Se, em 2002, 70\% dos programas de governo dos presidentes eleitos defendiam a redução da tributação sobre a atividade econômica ou a riqueza, em 2008 - ponto mais baixo - sua vigência havia caído 
para $23 \%$. A diferença entre os programas eleitos e derrotados é sensível especialmente no período 2006-2009, quando a Reforma Tributária passa a constar em taxas semelhantes nos dois grupos. Sua maior frequência ocorre no Brasil e no Uruguai (75\% dos programas analisados), bastante superior à média geral de $40 \%$.

A Regra 4 - Autonomia do Banco Central possui uma trajetória clara de decadência nos programas eleitos, perdendo o status de 40\% em 2002 para apenas 8\% em 2015. Entre as candidaturas derrotadas, a presença da regra não superou $23 \%$. Uma questão que pode ser aventada é a de a baixa popularidade da regra 4 ser impactada pela existência de Bancos Centrais independentes em países específicos. Essa hipótese, contudo, não parece se confirmar. Por exemplo, embora o Chile possua um Banco Central consideravelmente mais independente do que o da Colômbia (Dincer e Eichengreen, 2014), $50 \%$ dos programas de governo defendem a regra 4 no Chile e nenhum apoia essa regra na Colômbia. Preliminarmente, portanto, pode-se afastar essa circunstância específica. Salienta-se que, ao lado do Chile, a regra 4 é igualmente frequente nos programas do Peru e da Venezuela.

A Regra 5 - Câmbio de Mercado perdeu espaço tanto entre os programas vitoriosos quanto entre os derrotados após 2005, em um movimento que durou até 2011. Nesse último ano, a ideia da não intervenção na taxa de câmbio recuperou alguma popularidade. O país no qual a regra 5 é mais comum é a Costa Rica, 63\%, seguido por Brasil, Chile e Peru (50\%).

Frequente em mais de $50 \%$ dos programas de governo dos presidentes eleitos entre 2002 e 2013, a Regra 6 - Abertura Comercial é outra cuja presença verifica-se com maior ênfase nos programas das candidaturas derrotadas. Após um crescente interesse pela regra entre as candidaturas malsucedidas, em 2015 observou-se uma diferença acentuada: era defendida por $46 \%$ dos presidentes eleitos, contra $77 \%$ dos candidatos derrotados. De qualquer forma, trata-se de uma das quatro regras do $\mathrm{CW}$ mais resistentes, com pequena inflexão reparada no início do período da Onda Rosa. A regra 6 é muito frequente nos programas de governo do Chile (88\%), de El Salvador e do México (83\%).

Um desempenho semelhante é observado no que concerne à Regra 7 Investimento Externo Direto. Com queda modesta no início do período, a partir de 2006 a regra esteve presente em cerca de $50 \%$ dos programas de governo dos presidentes eleitos. Embora um pouco menos frequente nos programa derrotados (mínimo de 38\% entre 2006 e 2009), a regra 7 ganhou adesões também nesse campo nos últimos anos. El Salvador $(100 \%)$, Costa Rica e Equador (75\%) são seus maiores bastiões.

Com rejeição muito expressiva, a Regra 8 - Privatização não esteve presente em mais de um programa de governo de candidato eleito ou derrotado entre 2002 e 2015. Trata-se, portanto, de um termo praticamente banido do vocabulário político-ideológico da América Latina durante a Onda Rosa, com exceção de Costa Rica ( $25 \%$ dos programas) e 
Venezuela (33\%). Em todo o universo pesquisado, apenas $4 \%$ dos programas a apresentam.

Em um movimento já reparado pelas regras da Disciplina Fiscal, da Reforma Tributária, da Redução do Gasto Público e do Câmbio de Mercado, a Regra 9 Desregulamentação enfrentou perda de interesse a partir de 2006 nos programas de governo de candidatos eleitos. Constando de $70 \%$ deles em 2002, bateu em um mínimo de $31 \%$ entre 2013 e 2015 . No final do período, a regra voltou a frequentar os programas de governo, ainda que dos candidatos derrotados (62\% em 2015). Noções de desburocratização do governo e flexibilização das regras trabalhistas, em qualquer caso, não foram excluídas durante a Onda Rosa. Panamá (83\%), Brasil e Chile (75\%) são os países nos quais aparece mais comumente.

A Regra 10 - Direito de Propriedade manteve uma presença bastante constante, embora relativamente baixa, nos programas de governo dos presidentes eleitos, variando entre $27 \%$ e $38 \%$. Tornou-se, por outro lado, um tema que ganhou interesse entre as candidaturas malsucedidas, incrementando de $15 \%$ para $62 \%$ sua presença entre 2004 e 2015. A proteção da propriedade privada, assim, é a única regra do CW que claramente ganhou espaço durante a Onda Rosa, se considerados todos os programas de governo analisados. México, Peru (67\%) e Chile (63\%) conferem maior espaço à regra.

Com ainda mais força do que a Disciplina Fiscal, o Investimento Externo Direto e a Abertura Comercial, a Regra 11 - Estabilidade de Preços permaneceu com um patamar sólido de aceitação pelos programas de governo analisados. Mesmo que tenha perdido uma posição praticamente hegemônica ( $90 \%$ em 2002), a presença da regra não caiu para menos de $62 \%$ dos programas de governo vencedores e $69 \%$ dos derrotados. No geral, constou em $73 \%$ dos programas estudados. Todas as candidaturas presidenciais em quatro países - Brasil, Chile, México e Peru - vincularam essa regra a seus programas de governo.

A sensível queda do neoliberalismo na América Latina durante a Onda Rosa, percebida entre os anos de 2002 e 2006, refere-se à perda de importância acumulada de diversas regras. Redução do Gasto Público, Reforma Tributária e Disciplina Fiscal foram as que mais contribuíram para o enfraquecimento do neoliberalismo no subcontinente. Estabilidade de Preços e Desregulamentação ofereceram uma contribuição de relevância intermediária. Investimento Externo Direto, Abertura Comercial, Autonomia do Banco Central e Câmbio de Mercado contribuíram de forma muito modesta, enquanto Direitos de Propriedade e Privatização não contribuíram.

Partindo de posições hegemônicas no início do período, Disciplina Fiscal e, com ainda maior importância, Estabilidade de Preços foram baluartes do neoliberalismo no panorama ideológico da América Latina durante a Onda Rosa. As duas regras estiveram presentes em mais de $50 \%$ dos programas de presidentes eleitos durante todo o período de estudo (exceto nos últimos dois anos, para Disciplina Fiscal). Ambas as regras do CW também recuperaram espaço a partir da eleição de 2008. Abertura Comercial e 
Investimento Externo Direto, de forma mais modesta, se mantiveram em fração majoritária dos programas de presidentes eleitos.

Seis regras do CW parecem ter migrado, durante a Onda Rosa, para os programas de governo de candidatos mantidos na oposição. Tratando-se das candidaturas que chegaram em segundo lugar, presume-se, possuíram impacto político relevante. Esse é o caso inclusive de Disciplina Fiscal e Estabilidade de Preços, que se mantiveram com força ainda mais expressiva nos programas derrotados do que nos vencedores.

As demais quatro regras que se tornaram mais salientes nos programas rejeitados são: Abertura Comercial, Desregulamentação, Direito de Propriedade e Investimento Externo Direto. O grupo de candidaturas presidenciais derrotadas passou a apresentar as quatro regras referidas com mais intensidade a partir de 2010 , quando se acentuam as diferenças em relação aos candidatos eleitos. De fato, as forças que exerceram uma oposição ideologicamente próxima do neoliberalismo às lideranças da Onda Rosa no Brasil, no Uruguai e na Venezuela - e, em menor medida, no Chile, em El Salvador e no Equador - são fundamentais para explicar o aumento do interesse na América Latina pelas quatro regras destacadas. Estas diferem-se das regras Estabilidade de Preços (na qual concomitantemente eleva-se o interesse de candidatos eleitos e não eleitos) e Disciplina Fiscal (em relação à qual cai o interesse dos dois grupos, embora, entre os derrotados, com atraso). Trata-se, portanto, de um esforço específico da oposição à Onda Rosa para a manutenção e o incremento do espírito do neoliberalismo em seus respectivos países e, em consequência, na América Latina.

\section{Adesão ao Consenso de Washington: a análise de clusters e a versão mitigada (neoliberalismo do tripé macroeconômico)}

O indicador CW - Neoliberalismo fornece uma visão líquida, sem especificação, da adesão das candidaturas ao CW. Embora permita ranquear os programas conforme o volume de regras, não especifica quais as diferenças intrínsecas entre eles. Nada levaria a crer, por princípio, que determinadas regras - mesmo as mais frequentes - distribuem-se de maneira próxima à uniformidade entre os programas, ou em um grupo adscrito por critérios extrínsecos. Para fornecer uma interpretação sobre a interação das regras no conjunto dos 94 programas de governo, realizou-se uma análise de clusters (agrupamentos) ${ }^{15}$. A análise permitiu interpretar a existência de três grupos de candidaturas no universo analisado, conforme descritos na Figura 3.

\footnotetext{
15 Utilizando a análise de K-médias (SPSS 22), por exigência das variáveis dicotômicas, verificou-se a melhor estabilização do modelo com três clusters (na quarta interação). Teste post hoc (Bonferroni) rodado com os três clusters revelou variação não significativa entre pares para diversas variáveis, como ilustra a proximidade das presenças médias. A interpretação levou em consideração apenas as variações com significância no intervalo de 5\%.
} 
Os três agrupamentos são significativamente diferentes entre si. Há diferenças estatisticamente significativas entre os agrupamentos 1 e 2 nas regras Estabilidade de Preços, Redução do Gasto Público, Disciplina Fiscal, Reforma Tributária e Câmbio de Mercado. Os agrupamentos 2 e 3 são os mais diferentes entre si, incluindo na relação prévia a Desregulamentação, o Investimento Externo Direto, o Direito de Propriedade e a Abertura Comercial, e excluindo, apenas, o Câmbio de Mercado (no que a diferença entre os agrupamentos 2 e 3 não é significativa). Os agrupamentos 1 e 3 são mais semelhantes, mas existem diferenças estatisticamente significativas em Reforma Tributária, Câmbio de Mercado, Abertura Comercial, Investimento Externo Direto, Desregulamentação e Direito de Propriedade.

\section{Figura 3}

Adesão às regras do Consenso de Washington em três agrupamentos de candidaturas presidenciais (América Latina, 1999-2015)

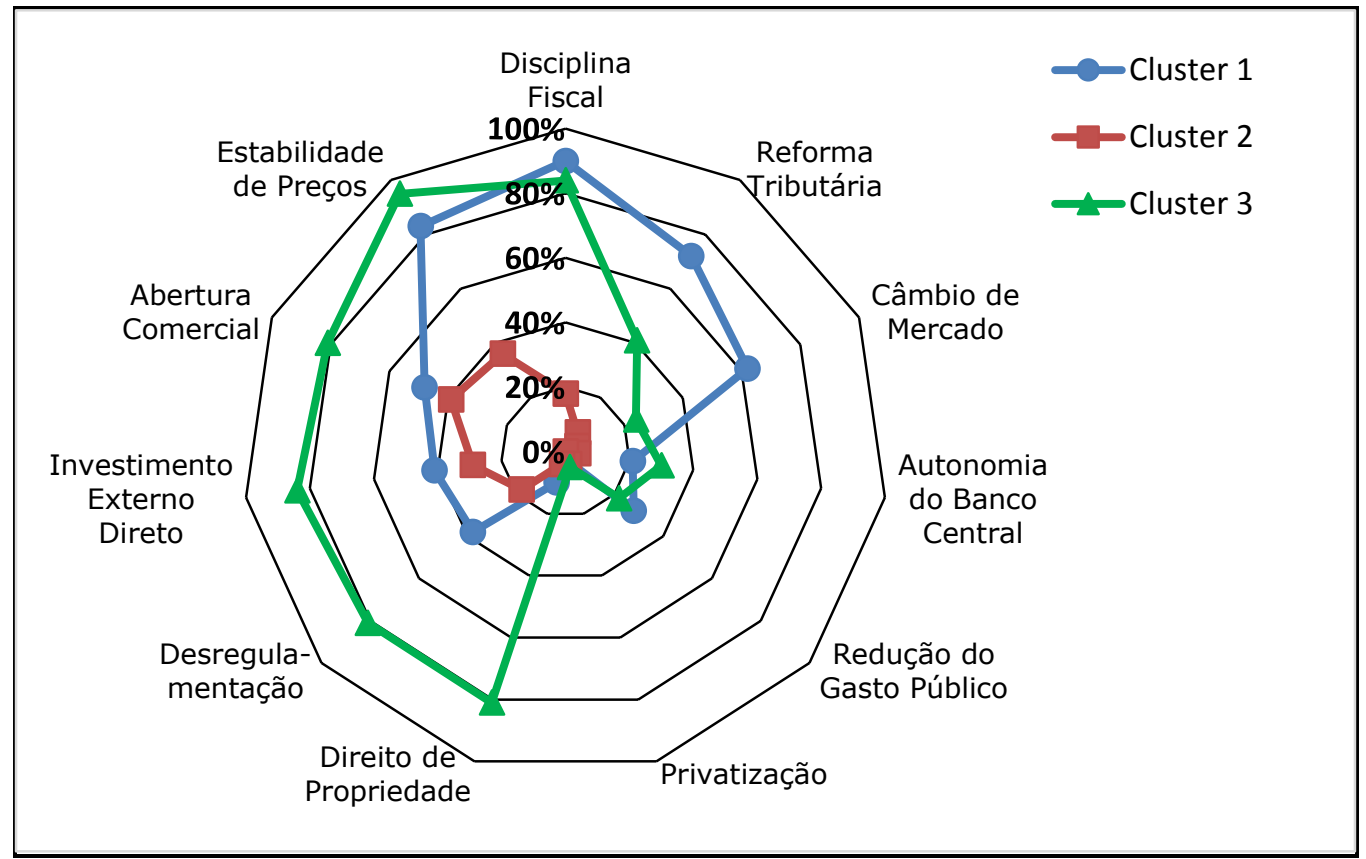

Fonte: Elaborada pelo autor com base em Oliveira, 2016a.

O aglomerado 2 é o conjunto de 28 programas de governo que mais profundamente rejeitam o CW, embora com concessões importantes para as regras Estabilidade de Preços, Abertura Comercial e, com menor relevância, Investimento Externo Direto. É, portanto, o agrupamento que mais claramente se divorcia do neoliberalismo. Também é o grupo central da Onda Rosa, concentrando 11 dos 23 programas identificados segundo o conceito mínimo definido anteriormente. O centro de interseção entre a Onda Rosa e o agrupamento 2 encontra-se na Bolívia e no Equador (todos os programas de 
governo do MAS e do PAIS), ramificando-se para Argentina e Venezuela (os dois últimos, dos três programas vitoriosos do FPV e do MVR/PSUV) e para o Brasil (programa do PT de 2014). Candidatos eleitos com plataforma do agrupamento 2 também governaram a Colômbia (PDU em 2014), a Costa Rica (PAC em 2014) e o Panamá (PRD e CD), embora esses países tenham sido excluídos da definição mínima de Onda Rosa.

O aglomerado 1 apresenta uma versão reduzida do neoliberalismo próxima ao conceito de tripé macroeconômico, reunindo câmbio flutuante (regra de Câmbio de Mercado), metas de inflação (Estabilidade de Preços) e metas de superávit primário (Disciplina Fiscal). É composto por 29 casos. A interseção entre a Onda Rosa e o agrupamento 1 está no Uruguai (todos os programas de candidatos eleitos do FA) e no Brasil (todos os programas de candidatos eleitos do PT - 2002, 2006, 2010 -, exceto o de 2014). Antes do Brasil, a Argentina (FPV) e a Venezuela (MVR) haviam abandonado o agrupamento 1 em favor do 2 após as eleições bem-sucedidas de, respectivamente, 2003 e 2000. No Chile, o PPD havia sido eleito com um programa do agrupamento 1 em 1999, mas no pleito seguinte o PS apresentou um programa inserido no agrupamento 3. Candidatos eleitos com programas de governo no agrupamento 1 governaram, ainda, a Costa Rica (dois mandatos do PLN) e a Colômbia (primeiro do PDU).

A adequação de um agrupamento ao "tripé" não estava prevista no desenho da pesquisa e emergiu a partir da análise empírica dos dados. Conforme Nassif (2015, p. 428), o conceito foi formado no Brasil para designar a estratégia macroeconômica adotada após o ataque especulativo de 1999. Ele está baseado em três políticas específicas, que podem ser assim resumidas: metas para a inflação, câmbio flutuante e superávits fiscais primários (Bresser-Pereira, 2006, p. 20; Biancarelli e Rossi, 2014, p. 21; Nassif, 2015, p. 428). Enquanto Bresser-Pereira (2006) fixa as regras do "tripé" como o núcleo central do projeto neoliberal, Biancarelli e Rossi (2014) consideram que não haveria contradição entre sua adoção e um modelo de desenvolvimento não neoliberal.

Por sua presença nos programas de governo de gestões que compõem a Onda Rosa, a adesão ao "tripé" parece ser uma âncora ideológica para manutenção do neoliberalismo ao longo do período. Além de suas disposições centrais, a presença da regra da Reforma Tributária também identifica o aglomerado 1, nesse caso em contraposição aos dois outros agrupamentos. Destaca-se que, para Clark e North (2018, p. 213), a política de tributação regressiva preservada no período é uma evidência de que os governos da Onda Rosa não se divorciaram plenamente do neoliberalismo.

No aglomerado 3 encontram-se os 37 dos 94 programas de governo estudados, que professam a versão mais abrangente que o neoliberalismo alcançou na América Latina dos anos 2000. Com exceção das regras Câmbio de Mercado e Reforma Tributária, esse agrupamento possui indicadores elevados em todas as regras que não são recusadas genericamente. Essas duas regras estão mais presentes nos programas do grupo do "tripé". Apenas os dois programas vitoriosos da FMLN, em El Salvador, e o programa do 
PS de 2005, no Chile, poderiam constar concomitantemente na definição de Onda Rosa e no agrupamento 3 (pois seus opositores eram ainda mais fortemente neoliberais). Candidatos eleitos com programas do agrupamento 3 governaram o México, o Peru e El Salvador por todo o período, o Chile em três ocasiões a partir de 2005, a Colômbia durante o período de Álvaro Uribe e Costa Rica e Panamá nas primeiras eleições analisadas (ver Quadros 2 e 3).

A variação do indicador CW - Neoliberalismo, utilizada para identificar a Onda Rosa, é captada pela divisão nos agrupamentos. Observem-se as médias do indicador: 0,14 para o agrupamento 2 (não neoliberal), 0,45 para o 1 (neoliberal do tripé macroeconômico) e 0,57 para o 3 (neoliberal). A análise de clusters permite especificar como um grupo determinado de programas de governo, geralmente inseridos na Onda Rosa, se relaciona com o neoliberalismo. Os governos do PT, no Brasil, e do FA, no Uruguai, principalmente, são tratados como exemplos de moderação. Do ponto de vista da ideologia programática professada em seus programas de governo, essa interpretação está correta.

Eles exibem uma espécie de neoliberalismo reduzido às diretrizes mais próximas da gestão macroeconômica - identificada como tripé macroeconômico. Rejeitam, contudo, as expectativas relacionadas ao setor externo (Abertura Comercial e Investimento Externo Direto) e as expectativas institucionais de influenciar o comportamento do setor privado (Direito de Propriedade e Desregulamentação). São essas mesmas quatro regras que ganharam maior interesse dos opositores à Onda Rosa no final do período analisado (Figura 2) e diferenciam positivamente o aglomerado 3, composto por candidaturas mais fortemente vinculadas ao neoliberalismo.

\section{Neoliberalismo e o debate sobre as duas esquerdas na Onda Rosa}

Uma das primeiras e mais difundidas interpretações da Onda Rosa na América Latina fala em duas esquerdas, uma radical, populista (da Venezuela, Bolívia, Equador e Argentina) e outra moderada, responsável (do Brasil, Uruguai e Chile) (Castañeda, 2006). A partir de uma revisão da literatura sobre as tipologias das esquerdas durante a Onda Rosa, Silva (2011, p. 241) destaca o uso normativo e polissêmico de categorizações genéricas como as de Castañeda, em análises que simplificam fenômenos complexos e divergentes em uma dualidade esquerda boa e má. Gallegos (2006) e Gonzalez (2019, p. 168), ademais, pontuam que a classificação de Castañeda corrobora com uma posição crítica à Onda Rosa.

Não faz parte do interesse central da presente pesquisa um esforço de tipologia das esquerdas durante a Onda Rosa, apenas no que ajuda a pensar a relação dessas forças políticas com o neoliberalismo. Especificamente nesse ponto, Silva (2011, p. 166) destaca que - entre as experiências que analisa - o PS chileno (principalmente), o FA uruguaio e o PT brasileiro "aceitaram em suas proposições alguns elementos do corpus teórico 
neoliberal", enquanto o MAS boliviano "manteve uma perspectiva mais radical e 'ofensiva', defendendo algo mais que a reforma ou a superação do neoliberalismo nos moldes implantados no continente" (Silva, 2011, p. 166).

Os programas de governo presidenciais analisados neste artigo contam uma história da Onda Rosa cujo enredo é mais sinuoso. No princípio, a Onda Rosa era uma esquerda apenas. Os partidos que chegaram à presidência de seus países no início da Onda Rosa comungavam não de uma visão antagônica ao neoliberalismo, mas de uma visão mitigada, centrada no "tripé": PPD no Chile (1999), MVR na Venezuela (2000), PT no Brasil (2002), FPV na Argentina (2003) e FA no Uruguai (2004).

Entre esse ciclo eleitoral e o seguinte, algo mudou na cena política da América Latina. A primeira eleição vitoriosa do MAS, em 2005, na Bolívia, é um sinal. O programa de governo de Evo Morales em 2005 incorporou algumas regras do CW - Autonomia do Banco Central, Câmbio de Mercado e Abertura Comercial -, enquanto no anterior, de 2002, não havia nenhuma. Ainda assim, a plataforma do MAS de 2005 é a primeira vitoriosa que não apenas rejeitava genericamente o neoliberalismo, mas também não adotava a visão do "tripé".

Depois de Evo Morales, elege-se Rafael Correa (PAIS, Equador, em 2006) com um programa de governo ausente do neoliberalismo. Ao grupo de presidentes eleitos que rejeitam o CW em seus programas de governo, somam-se, apenas em suas segundas candidaturas vitoriosas, o MVR venezuelano e o FPV argentino. Embora continuamente diminuindo a presença do CW em seus programas, o PT apenas abandona o "tripé" em 2014, na reeleição de Dilma Rousseff. No Chile, ao menos em um primeiro momento, a Concertação - com a candidatura do PS, de 2005 - torna-se mais neoliberal, com um programa de governo próximo à visão mais forte do CW. Assim como o FMLN de El Salvador, que, nas duas eleições vitoriosas pesquisadas, permanece com seu programa de governo dentro do grupo neoliberal.

O Quadro 2 sintetiza essa compreensão sobre as diferentes esquerdas presentes nos programas de governo dos presidentes eleitos na Onda Rosa da América Latina. A Onda Rosa, pela interpretação mínima incialmente trabalhada, agrega plataformas ideológicas dos três grupos de adesão ao neoliberalismo. De qualquer forma, a Onda Rosa propriamente neoliberal poderia ser identificada apenas no Chile e em El Salvador e, durante o período, apenas o Uruguai se manteve na perspectiva do "tripé". Todos os demais países - Argentina, Bolívia, Brasil, Equador e Venezuela - iniciam ou chegam a programas de governo não neoliberais (no grupo de menor presença das regras do $\mathrm{CW}$ ). 
Quadro 2

Programas de governo dos presidentes eleitos na Onda Rosa, por país, adesão ao neoliberalismo, sigla do partido patrocinador da candidatura e ano da eleição (América Latina, 1999-2015)

\begin{tabular}{|l|c|c|c|}
\hline & $\begin{array}{c}\text { Neoliberal } \\
\text { (Cluster 3) }\end{array}$ & $\begin{array}{c}\text { Neoliberal do tripé } \\
\text { macroeconômico } \\
\text { (Cluster 1) }\end{array}$ & $\begin{array}{c}\text { Não neoliberal } \\
\text { (Cluster 2) }\end{array}$ \\
\hline Argentina & & FPV (2003) & FPV $(2007,2011)$ \\
\hline Bolívia & & PT $(2002,2006,2010)$ & MAS $(2005,2009,2014)$ \\
\hline Brasil & & PPD (1999) & \\
\hline Chile & PS (2005) & & \\
\hline El Salvador & FMLN (2009, 2014) & & PAIS (2006, 2009, 2013) \\
\hline Equador & & FA (2004, 2009, 2014) & \\
\hline Uruguai & & MVR (2000) & MVR/PSUV (2006, 2012) \\
\hline Venezuela & & &
\end{tabular}

Fonte: Elaborado pelo autor com base em Oliveira, 2016a.

Os programas dos presidentes eleitos no período estudado e que não foram enquadrados no conceito mínimo de Onda Rosa são apresentados no Quadro 3. Percebese a concentração no grupo 3, neoliberal: 14 do total (58\%). Outros 10 programas dividem-se entre os grupos não neoliberal e neoliberal do tripé macroeconômico. Os governos que antecederam a Onda Rosa na Bolívia, em El Salvador e no Uruguai pertencem aos mesmos grupos de seus sucessores. Como não foram analisadas eleições anteriores na Argentina, no Brasil, no Chile e na Venezuela, não é possível discernir sobre um eventual efeito de trajetória na origem das experiências nacionais do "pós-neoliberalismo". Entre os casos estudados, apenas no Equador percebe-se uma inflexão nos programas de governo dos presidentes eleitos antes e após a Onda Rosa. 
Quadro 3

Programas de governo dos presidentes eleitos, exceto Onda Rosa, por país, adesão ao neoliberalismo, sigla do partido patrocinador da candidatura e ano da eleição (América Latina, 1999-2015)

\begin{tabular}{|l|c|c|c|}
\hline & $\begin{array}{c}\text { Neoliberal } \\
\text { (Cluster 3) }\end{array}$ & $\begin{array}{c}\text { Neoliberal do tripé } \\
\text { macroeconômico (Cluster1) }\end{array}$ & $\begin{array}{c}\text { Não neoliberal } \\
\text { (Cluster 2) }\end{array}$ \\
\hline Argentina & & & PRO (2015) \\
\hline Bolívia & & & MNR (2002) \\
\hline Chile & RN (2009); PS (2013) & PDU (2010) & PDU (2014) \\
\hline Colômbia & 1CO (2002, 2006) & PLN (2006) \\
\hline Costa Rica & PLN (2010) & \\
\hline El Salvador & Arena (2004) PAC (2014) & \\
\hline Equador & SP (2004) & & PRD (2004); CD (2009) \\
\hline México & PAN (2000, 2006); PRI (2012) & & \\
\hline Panamá & PAN (2014) & & \\
\hline Peru & PP (2001); Apra (2006); & & \\
\hline Uruguai & PNP (2011) & & \\
\hline
\end{tabular}

Fonte: Elaborado pelo autor com base em Oliveira, 2016a.

Os programas de governo presidenciais também contam a história de duas oposições à Onda Rosa. Uma que se manteve fiel ao $\mathrm{CW}$ e outra que o abandonou. $\mathrm{O}$ segundo é o caso das oposições na Argentina e na Bolívia, únicos países nos quais se esboçou um consenso em torno do "pós-neoliberalismo". Na Argentina, tal consenso perceptível na Figura 1, com a queda geral do indicador CW-Neoliberalismo - mostrou-se insuficiente para direcionar a política pública do novo governo. Em vez de um governo "pós-neoliberal", como poderia indicar o programa de governo do PRO em 2015, englobado no cluster 2 (não neoliberal), Mauricio Macri adotou uma política de retomada gradual do neoliberalismo (Natanson, 2018).

No Brasil, no Uruguai, no Equador e na Venezuela, os partidos e forças mantidas na oposição durante a Onda Rosa preservaram ou incrementaram a presença do CW em seus programas de governo. Com exceção do programa do PSDB brasileiro de 2010 e do SP equatoriano de 2013, todas as demais candidaturas de oposição nesses países agruparam-se na visão mais consistente do neoliberalismo, o grupo 3 (os dois citados mantiveram-se na perspectiva do tripé macroeconômico). Portanto, como regra geral, a adesão ao neoliberalismo, de fato, expressa uma diferenciação ideológica entre os partidos 
e presidentes que participaram da Onda Rosa e de seus principais antagonistas eleitorais. O corte de distinção não se situa no $\mathrm{CW}$ como pressuposto da política macroeconômica ("tripé"), mas em sua utilização como visão organizadora da inserção internacional dos países e das instituições relativas ao comportamento dos agentes econômicos.

Os dois países com maior diferença ideológica em torno do neoliberalismo no final do período são Brasil e Venezuela (nas eleições de 2014 e 2012, respectivamente). Os quadros na Figura 1 mostram o formato de "boca de jacaré" nas linhas dos programas vencedores e derrotados, bem como a manutenção de uma lacuna expressiva entre as tendências ao longo do tempo. A análise de cluster certifica que, ao menos na última eleição, situação e principal oposição estavam nos grupos mais contrastantes (não neoliberal e neoliberal). O mesmo não ocorreu no Uruguai e no Equador, com uma distância menos expressiva entre os contendores principais, e um deles, nas últimas eleições, aderente ao neoliberalismo mitigado do tripé macroeconômico.

\section{Considerações finais}

A ideia de Onda Rosa tornou-se uma forma recorrente de denominar o fenômeno da "guinada à esquerda" dos governos na América Latina dos anos 2000, após as políticas neoliberais dos governos precedentes e em resposta a elas. O presente artigo dedicou-se a investigar a presença do neoliberalismo, interpretado conforme as disposições do Consenso de Washington, nos programas de governo de 13 países da América Latina. Foram analisados 94 programas de governos, incluindo candidatura eleita e segunda colocada em número de votos, de 47 eleições presidenciais. Identificou-se o fenômeno da Onda Rosa em oito diferentes países: Argentina, Bolívia, Brasil, Chile, El Salvador, Equador, Uruguai e Venezuela. Nesses países, foi eleita ao menos em duas eleições consecutivas a candidatura cujo programa de governo apresentava menor presença do CW, segundo a definição mínima de Onda Rosa discutida anteriormente. Esta alcançou, portanto, 23 mandatos presidenciais, ou seja, 49\% dos mandatos cujas eleições presidenciais foram analisadas. Em cinco países não ocorreu a Onda Rosa: Colômbia, Costa Rica, México, Panamá e Peru.

Se, por um lado, é inegável que o CW perdeu força na política da América Latina do século XXI, por outro, deve-se admitir que a ideologia neoliberal permaneceu não apenas como um vetor importante da diferenciação política/partidária das candidaturas presidenciais, mas, também, como conteúdo programático dos presidentes eleitos. A regra da Estabilidade de Preços, como fundamento da política econômica, e a Disciplina Fiscal demonstram de maneira mais clara a presença do CW na América Latina dos anos 2000. Elas mantiveram-se tanto nos programas de governo claramente neoliberais como naqueles que desenvolveram uma visão mitigada (em torno no tripé macroeconômico). É possível que tal força ideológica responda à fragilidade, ao menos política, das opções 
oferecidas pela economia heterodoxa para tratar a questão da inflação - como repara Notermans (2000, p. 225) em relação à social-democracia europeia.

Quatro regras apareceram com força em programas de governo antagônicos às candidaturas da Onda Rosa e ganharam espaço nos programas das oposições ao longo dos últimos anos analisados: Desregulamentação, Direito de Propriedade, Abertura Comercial e Investimento Externo Direto. Essas regras, fundamentadas em uma interpretação coerente sobre a inserção internacional dos países e os incentivos institucionais do comportamento dos agentes econômicos, são aquelas que identificam programas de governo mais coerentemente organizados em torno da ideologia neoliberal. Adotam o CW inclusive como orientação de intervenção microeconômica. Apenas no Chile e em El Salvador governos da Onda Rosa foram eleitos com programas de governo neoliberais nessa acepção.

Se por uma esquerda "moderada" se quer identificar programas de governo que aceitam noções macroeconômicas ortodoxas do tripé macroeconômico, mas mantêm o controle sobre áreas microeconômicas, ela esteve presente não apenas no Uruguai e no Brasil. Também está reportada nos primeiros programas analisados na Argentina e na Venezuela. Os presidentes eleitos na Onda Rosa que inauguram uma forte rejeição do neoliberalismo são os da Bolívia e do Equador, aqueles ligados à visão do "Buen Vivir". Venezuela, Argentina e, mais tarde, Brasil, também elegeram presidentes com programas de governo afastados dessa interpretação de uma esquerda "moderada". Apenas no Uruguai todos os programas de governo da Onda Rosa permaneceram no grupo do neoliberalismo do "tripé".

Nesse ponto específico, o artigo permitiu descrever com maior complexidade a visão das duas esquerdas latino-americanas - não como discriminação de casos nacionais, mas em suas trajetórias. Embora diferenças ideológicas possam ser apreendidas entre os casos nacionais, a estilização elevada do conteúdo ideológico proposto durante a Onda Rosa implicada no conto das duas esquerdas de Castañeda (2006) suprime diferenças substanciais e transformações que ocorreram ao longo dos anos. Potencialmente, pensar a priori em termos de duas esquerdas prejudica uma compreensão adequada da relação do fenômeno político da Onda Rosa com o neoliberalismo e o CW.

Algumas considerações podem ser oferecidas à guisa de aberturas para futuras investigações. Enquanto insumo da representação, a ideologia programática pode ser compreendida como categoria na investigação da congruência política ou da accountability vertical. Trata-se de compreender a capacidade de os programas de governo servirem como proxy do discurso programático mais genericamente considerado, estruturarem a competição político-eleitoral e, em um segundo momento, permitirem o controle da política pública dos governos eleitos pelos cidadãos.

Na América Latina, tais questões foram levantadas a respeito do neoliberalismo nos anos 1980 e 1990 por Stokes (2001) e, de forma mais abrangente, por Kitschelt e 
outros (2010). Constrangimentos econômicos estruturais, como a disponibilidade de hidrocarbonetos (Weyland, 2009), ou o contexto externo, como o preço das commodities e as taxas de juros internacionais (Campello, 2015), por exemplo, podem impactar a habilidade de os governos seguirem as disposições ideológicas que lançam nas eleições, ou mesmo limitar o rol de políticas imaginadas e articuladas nas eleições. Em que pesem as importantes implicações dessas investigações, cumpre destacar que o fenômeno ideológico, enquanto construção de sentidos na disputa eleitoral e fora dela, preserva uma autonomia tanto empírica quanto acadêmica.

O mesmo pode ser afirmado em relação às clivagens, classes e movimentos sociais. Gonzalez (2019) repara que o conceito de Onda Rosa ficou vinculado ao fenômeno políticoeleitoral. Acabou, assim, por retirar a visibilidade das lutas e movimentos sociais que resistiram ao neoliberalismo em cada contexto nacional e cujas experiências foram apropriadas, moldando as alternativas políticas. O foco da presente pesquisa resumiu-se à presença e à ausência do Consenso de Washington nos programas de governo presidenciais da Onda Rosa da América Latina. Revelou a manutenção de estratégias do neoliberalismo em parte expressiva dos programas dos presidentes "pós-neoliberais". Um outro desafio seria investigar a dimensão positiva da Onda Rosa, multifacetada em noções como "novo-desenvolvimentismo" e "buen vivir". Conhecer seu conteúdo positivo, bem como sua conexão com a experiência, é fundamental para compreender se a ideologia "pós-neoliberal" interpelou os sujeitos coletivos em conexões de representação política, abrindo a possiblidade para propagações da Onda Rosa na América Latina.

\section{Referências bibliográficas}

Anderson, P. Balanço do neoliberalismo. SAder, E.; Gentili, P. (eds.). Pós-neoliberalismo: as políticas sociais e o Estado democrático. Rio de Janeiro: Paz e Terra, 1998.

ANDRADE, D. P. "O que é o neoliberalismo? A renovação do debate nas ciências sociais". Sociedade e Estado, vol. 34, no 1, p. 211-239, 2019.

ANGEL, A.; LóPEZ-LONDOÑO, L. M. "Delinking rhetorics of neoliberalism: an analysis of South American leftist presidents' speeches". Journal of International and Intercultural Communication, vol. 12, no 1 , p. 43-62, 2019.

BAKER, A.; GREENE, K. F. "The Latin American left's mandate: free market policies and issue voting in new democracies". World Politics, vol. 63, no 1, p. 43-77, 2011.

BARDin, L. Análise de conteúdo. Lisboa: Edições 70, 1995.

Biancarelli, A.; Rossi, P. "A política macroeconômica em uma estratégia social-desenvolvimentista". Revista Brasileira de Planejamento e Orçamento, vol. 4, no 1, p. 21-38, 2014.

BoIto JR., A. "A crise política do neodesenvolvimentismo e a instabilidade da democracia". Crítica Marxista, no 42, p. 155-162, 2016.

BOITO JR., A.; BERRINGER, T. "Brasil: classes sociais, neodesenvolvimentismo e política externa nos governos Lula e Dilma". Revista de Sociologia e Política, vol. 21, n 47, p. 31-38, 2013.

BORón, A. O pós-neoliberalismo é uma etapa em construção. In: SADER, E.; Gentili, P. (eds.). Pósneoliberalismo: as políticas sociais e o Estado democrático. Rio de Janeiro: Paz e Terra, 1998. 
Bresser-Pereira, L. C. "O novo desenvolvimentismo e a ortodoxia convencional". São Paulo em Perspectiva, vol. 20, no 3, p. 5-24, 2006.

Bresser-PereirA, L. C.; Theuer, D. "Um Estado novo-desenvolvimentista na América Latina?". Economia e Sociedade, vol. 21, no especial, p. 811-829, 2012.

CAMPELlo, D. The politics of market discipline in Latin America: globalization and democracy. Cambridge: Cambridge University, 2015.

CARREIRÃo, Y. S. "Representação política como congruência entre as preferências dos cidadãos e as políticas públicas: uma revisão da literatura internacional", Opinião Pública, vol. 21, no 2, p. 393430, 2015.

CastañedA, J. "Latin America's left turn". Foreign Affairs, vol. 85, no 3, p. 28-43, 2006.

CLARK, T. D. The paradox of the neoliberal developmentalist State: reconstructing the capitalist elite in Pinochet's Chile. In: NORTH, L. L.; CLARK, T. D. (orgs.). Dominant elites in Latin America: from neoliberalism to the 'Pink Tide'. Londres: Palgrave Macmillan, 2018.

CLARK, T. D.; NORTH, L. L. The limits of democratization and social progress: domination and dependence in Latin America. In: NORTH, L. L.; CLARK, T. D. (orgs.). Dominant elites in Latin America: from neo-liberalism to the 'Pink Tide'. Londres: Palgrave Macmillan, 2018.

Coutinho, M. "Movimentos de mudança política na América do Sul contemporânea". Revista de Sociologia e Política, no 27, p. 107-123, 2006.

Cubillo-Guevara, A. P. "Genealogía inmediata de los discursos del buen vivir en Ecuador (19922016)". América Latina Hoy, vol. 74, p. 125-144, 2016.

CuestAs-CAZA, J.; "Sumak Kawsay between western post-development and Andean philosophy". Ánfora, vol. 26, no 47, p. 111-142, 2019.

Dincer, N.; EICHengreen, B. "Central Bank transparency and independence". International Journal of Central Banking, vol. 10, no 1, p. 189-251, 2014.

Evans, P.; SeWELL, W. Neoliberalism: policy regimes, international regimes, and social effects. In: HALL, P.; LAMONT, M. (orgs.). Social resilience in the neoliberal era. Cambridge: Cambridge University, 2012.

Fernandes, A. S. A.; Borges, A. "Ideias fora do lugar: o neoliberalismo como categoria de análise das políticas sociais no Brasil". Organização e Sociedade, vol. 15, no 46, p. 13-37, 2008.

FisCher, K.; PLEHWE, D. "Redes de think tanks e intelectuales de derecha en América Latina". Nueva Sociedad, no 245, p. 70-86, 2013.

Gallegos, F. R. "Mucho más que dos izquierdas". Nueva Sociedad, no 205, p. 30-44, 2006.

GARretón, M. A., et al. América Latina no século XXI: em direção a uma nova matriz sociopolítica. Rio de Janeiro: FGV, 2007.

GaUdichaud, F. "Fim de ciclo na América do Sul? Movimentos populares, governos 'progressistas' e alternativas ecossocialistas". Lutas Sociais, vol. 20, no 36, p. 52-65, 2016.

. "Amérique Latine: les gouvernements 'progressistes' dans leur labyrinthe". Recherches Internationales, no 115, 2019.

Gonzalbo, F. E. Historia mínima del neoliberalismo. Ciudad de México: Colegio de México, 2015.

Gonzalez, M. The ebb of the Pink Tide: the decline of the left in Latin America. London: Pluto Press, 2019.

Gros, D. B. "Institutos liberais, neoliberalismo e políticas públicas na Nova República". Revista Brasileira de Ciências Sociais, vol. 19, no 54, p. 143-159, 2004.

Henry, P.; Moscovici, S. "Problèmes de l'analyse de contenu". Langages, vol. 3, no 11, p. 36-60, 1968. 
KITSCheLT, H., et al. Latin American party systems. Cambridge: Cambridge University, 2010.

LASSWELL, H. (org.). A linguagem da política. Brasília, DF: UnB, 1982.

LOPES, D. B.; FARIA, C. A. P. "When foreign policy meets social demands in Latin America". Contexto Internacional. vol. 38, $\mathrm{n}^{\circ} 1$, p. 11-53, 2016.

LORA, E.; OLIVEIRA, M. "The electoral consequences of the Washington consensus". Economia, vol. 5, n० 2, p. 1-61, 2015.

Lovemam, B. Chile: the legacy of Hispanic capitalism. Oxford: Oxford University, 2001.

MARANGos, J. "The evolution of the term 'Washington Consensus'". Journal of Economic Surveys, vol. 23, n०2, p. 350-384, 2009.

Murillo, M. V.; Oliveros, V.; Vaishanav, M. "Electoral revolution or democratic alternation?". Latin America Research Review, vol. 45, no 3, p. 87-114, 2010.

NAIM, M. "Fads and fashion in economic reforms: Washington consensus or Washington confusion?". Third World Quarterly, vol. 21, no 3, p. 505-528, 2000.

NASSIF, A. "As armadilhas do tripé da política macroeconômica brasileira". Revista de Economia e Política, vol. 35, no 3, p. 426-443, 2015.

NatAnson, J. "Mauricio Macri en su ratonera". Nueva Sociedad, no 276, p. 24-33, 2018.

Notermans, T. Money, markets, and the State: social democratic economic policies since 1918. Cambridge: Cambridge University, 2000.

OliveirA, A. N. C. "A ideologia econômica dos presidentes na América Latina: um indicador a partir dos programas de governo eleitorais". Indicadores Econômicos FEE, vol. 43, nº 1, p. 83-98, 2015.

As promessas dos presidentes: democracia representativa em 16 países da América Latina. Porto Alegre: FEE, 2016a.

"Banco de asserções programáticas: banco de dados". 2016b. Disponível em:

<https://www.fee.rs.gov.br/wp-content/uploads/2016/05/20160517bap.2015.xlsx>. Acesso em: mar. 2020.

RODRIK, D. "Goodbye Washington Consensus, Hello Washington Confusion?". Journal of Economic Literature, vol. 44, no 4, p. 973-987, 2006.

RUCKERT, A.; MACDONALD, L.; PROULX, K. "Post-neoliberalism in Latin America: a conceptual review". Third World Quarterly, vol. 38, no 7, p. 1.583-1.602, 2017.

SAder, E.; Gentili, P. (eds.). Pós-Neoliberalismo: as políticas sociais e o Estado democrático. Rio de Janeiro: Paz e Terra, 1998.

SALLUM JR., B.; GOULART, J. O. "O Estado brasileiro contemporâneo: liberalização econômica, política e sociedade nos governos FHC e Lula". Revista de Sociologia e Política, vol. 24, no 60, p. 115-135, 2016.

Silva, E. Chile. In: Vanden, H.; Prevost, G. (eds.). Politics of Latin America: the power game. Oxford: Oxford University, p. 437-482, 2002.

SILVA, F. P. Vitórias na crise: trajetórias das esquerdas latino-americanas contemporâneas. Rio de Janeiro: Ponteiro, 2011.

. "O fim da Onda Rosa e o neogolpismo na América Latina". Revista Sul-Americana de Ciência Política, vol. 4, n² 2, p. 165-178, 2019.

SILVA, K. P.; GUEDES, A. L. "Buen vivir andino: resistência e/ou alternativa ao modelo hegemônico de desenvolvimento". Cadernos EBAPE.BR, vol. 15, n 3, p. 682-693, 2017. 
Stiglitz, J. E. Is there a Post-Washington Consensus?. In: SerRA, N.; StiglitZ, J. E. (eds.). The Washington Consensus reconsidered: toward a new global governance. Oxford: Oxford University, p. 41-56.2, 2008.

STOKES, S. C. Mandates and democracy: neoliberalism by surprise in Latin America. Cambridge: Cambridge University, 2001.

Therborn, G. Pós-neoliberalismo. In: SAder, E.; Gentili, P. (orgs.). Pós-neoliberalismo: as políticas sociais e o Estado democrático. Rio de Janeiro: Paz e Terra, 1998.

UnDURRAGA, T. "Neoliberalism in Argentina and Chile: common antecedents, divergent paths". Revista de Sociologia e Política, vol. 23, nº 55, p. 11-34, 2015.

VAnden, H.; PreVost, G. The political economy of Latin America. In: VANDEn, H.; PreVost, G. (eds.). Politics of Latin America: the power game. Oxford: Oxford University, p. 146-176, 2002.

WEYLAND, K. "The rise of Latin America's two lefts: insights from rentier State theory". Comparative Politics, vol. 41, no 2, p. 146-164, 2009.

WiLLIAMSON, J. What Washington means by policy reform. In: WilliamSON, J. (ed.). Latin American adjustment: how much has happened? 1991. Disponível em:

https://www.wcl.american.edu/hracademy/documents/Williamson1990WhatWashingtonMeansbyPoli cyReform.pdf Acesso em: 7 jul. 2017.

1.329-1.336, 1993

"Democracy and the 'Washington Consensus'". World Development, vol. 21, no 8, p.

A short history of the Washington Consensus. In: SERRA, N.; STIGLITZ, J. E. (eds.). The Washington Consensus reconsidered: toward a new global governance. Oxford: Oxford University, p. 14-30, 2008.

\begin{abstract}
Lasting neoliberalism: the Washington Consensus in the Latin American Pink Tide

This research aims to investigate the continuity of neoliberalism in the Latin America electoral politics during the Pink Tide, showing its presence in the presidential platforms launched from 1999 to 2015. A content analysis, based on the Washington Consensus, which is a kind of neoliberal manifesto, is used as an approach in this research. The analysis used 94 platforms from 47 presidential elections that took place in 13 Latin American countries. The research reveals that neoliberalism in fact has lost ground and the Washington Consensus rules, such as privatization and reduction in public spending, have been emphatically rejected. Meanwhile the ground established by rules such as inflation control and public deficit reduction presents the neoliberal resilience during the Pink Tide, even in nonneoliberal presidential platforms. As far as it measures the presence of the Washington Consensus in Latin America political scene after 2000, this study helps to ponder on the anti-neoliberal agenda limits and the basis of the resumption of the ideology in the subcontinent.
\end{abstract}

Keywords: ideology; presidential elections; electoral platforms; political parties

\title{
Resumen
}

Neoliberalismo perdurable: el Consenso de Washington en la Marea Rosa Latinoamericana

Esta investigación tiene como objetivo averiguar la continuidad del neoliberalismo en la política electoral de América Latina durante la Marea Rosa, mostrando su presencia en las plataformas presidenciales lanzadas desde 1999 hasta 2015. Se utiliza en esta investigación un análisis de contenido, como un enfoque basado en el Consenso de Washington, que es una especie de manifiesto neoliberal. El análisis utilizó 94 plataformas de 47 elecciones presidenciales que se llevaron a cabo en 13 países latinoamericanos. La investigación revela que, de hecho, el neoliberalismo ha perdido terreno. Algunas reglas del Consenso de Washington, como la privatización y la reducción del gasto público, han sido rechazadas enfáticamente. Mientras tanto, el terreno establecido por reglas como el control de la inflación y la reducción del déficit público presenta la resistencia neoliberal durante la 
Marea Rosa, incluso en plataformas presidenciales no neoliberales. En la medida en que evalúa la presencia del Consenso de Washington en escenario político en América Latina después del 2000, este estudio ayuda a reflexionar sobre los límites de la agenda anti neoliberal y las bases de la reanudación de la ideología en el subcontinente.

Palabra claves: ideología; elecciones presidenciales; programas de gobierno; partidos políticos

\section{Résumé}

Néolibéralisme durable: le Consensus de Washington sur la Vague Rose Latino-américaine

Cette recherche a pour objectif d'étudier la continuité du néolibéralisme dans la politique électorale en Amérique Latine pendant la vague rose, en montrant sa présence dans les programmes présidentiels lancés de 1999 à 2015. Une analyse du contenu, basée sur le Consensus de Washington, qui est une sorte de manifeste néolibéral, est utilisé comme une approche dans cette recherche. L'analyse a utilisé 94 programmes issus de 47 élections présidentielles qui ont eu lieu dans 13 pays d'Amérique Latine. La recherche révèle que le néolibéralisme a en fait perdu du terrain et que les règles du Consensus de Washington, telles que la privatisation et la réduction des dépenses publiques, ont été catégoriquement rejetées. Le terrain établi par des règles telles que le contrôle de l'inflation et la réduction du déficit public présent la résilience néolibérale pendant la vague rose, même dans les programmes présidentiels non néolibéraux. Dans la mesure où elle évalue la présence du Consensus de Washington sur la scène politique de l'Amérique Latine après 2000, cette étude permet de réfléchir aux limites de l'agenda anti-néolibéral et aux bases de la reprise de l'idéologie dans le continent.

Mot-clés: ideologie; élections presidentielles; programmes electorales, partis politiques

Artigo submetido à publicação em 19 de junho de 2019. Versão final aprovada em 4 de março de 2020.

Opinião Pública adota a licença Creative Commons CC-BY.

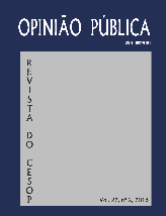

